\title{
Computational Study of Combustor-Turbine Interactions
}

\author{
Kenji Miki *, Meng-Sing Liou ${ }^{\dagger}$ \\ NASA Glenn Research Center, \\ Cleveland, Ohio 44135, USA
}

\begin{abstract}
The Open National Combustion Code (OpenNCC) is applied to the simulation of a realistic combustor configuration (Energy Efficient Engine $\left(\mathbf{E}^{3}\right)$ ) in order to investigate the unsteady flow fields inside the combustor and around the first stage stator of a high pressure turbine (HPT). We consider one-twelfth (24 degrees) of the full annular $\mathrm{E}^{3}$ combustor with three different geometries of the combustor exit: one without the vane, and two others with the vane set at different relative positions in relation to the fuel nozzle (clocking). Although it is common to take the exit flow profiles obtained by separately simulating the combustor and then feed it as the inflow profile when modeling the HPT, our studies show that the unsteady flow fields are influenced by the presence of the vane as well as clocking. More importantly, the characteristics (e.g., distribution and strength) of the high temperature spots (i.e., hot-streaks) appearing on the vane significantly alters. This indicates the importance of simultaneously modeling both the combustor and the HPT to understand the mechanics of the unsteady formulation of hot-streaks.
\end{abstract}

\section{Introduction}

Due to the ambitious demands of a highly fuel-efficient and environmentally friendly jet engine, we are faced with technical challenges in designing the combustor and high pressure turbine (HPT) stages. One of the issues that greatly affects the blade life and overall gas turbine (GT) durability is the existence of hotstreaks. The pronounced non-uniform high temperature spots are often seen on the blade surface. To avoid hot-streaks, the distribution of the cooling air holes needs to be carefully determined. Although the design and investigation of heat transfer of HPT has been done for decades, a full understanding of the formation mechanism of hot-streaks has not yet been achieved. Combustion dynamics is another important issue, which could result in catastrophic failure of a GT. The analysis of the combustion dynamics is extremely complicated, since this is a multi-physical problem controlled by combustion, atomization/vaporization of liquid spray fuel, and turbulent flow fields. It is obvious that both hot-streaks and combustion dynamics should be seen as a components interaction problem (i.e., combustor-turbine interactions shown in Fig. 1 ), which to this date is still not understood. In this study, we will use a modern computational fluid dynamics (CFD) tool, Open National Combustion Code (OpenNCC), to attempt to gain insights into this complicated problem.

The difficulty in investigating such a component interaction problem is threefold. First, the conventionally used CFD formulation, such as Reynolds-averaged Navier-Stokes (RANS) equations, appear inadequate to capture the inherent detailed dynamics, although it enjoys the advantage of providing a reasonably accurate "steady state" solution in a computationally cheap manner. A consensus is that a high-fidelity 3D "unsteady" model, such as Large eddy simulation (LES) and Direct Numerical Simulation (DNS), is required to properly address the dynamic nature of the interaction process. It is important to use a well-calibrated turbulence model to accurately capture unsteady turbulence levels, which is one of the key factors in determining the velocity fields and heat transfer on the vane surface. ${ }^{3}$ It is worth mentioning that the turbulence level at the combustor exit is greatly influenced by how we model the interaction between the dilution airflow and the main swirling flow with the chosen turbulence model. Using this type of CFD tool, we need a large number of grids to resolve the near wall regions, thus significantly increasing the computational cost.

\footnotetext{
*Postdoctoral Researcher, AIAA Member

†Senior Technologist, AIAA Fellow
} 
Secondly, a realistic boundary condition is essential. For instance, prediction of the hot streaks is highly dependent on how the distribution of the cooling air holes is chosen. Also, it is not clear whether the periodic boundary condition in the circumferential direction is adequate (needless to say, simulating a full combustor is definitely more realistic and gives a better solution).

Thirdly, this is a multi-scale problem in terms of time and length. The time scale of chemical reaction is much smaller than that of the combustion dynamics and the flow motions. Also, compared with the length of the combustor and turbine, the smallest scale (e.g., near wall grid size) is much smaller. Therefore, the total computational time is strongly dependent on how we choose these parameters, which are unlear. For instance, to capture the low frequency combustion dynamics $(\sim 10-200[\mathrm{~Hz}])$, we need to run at least one million steps with a typical computational time step $(\sim 1 \mathrm{e}-6-1 \mathrm{e}-7[\mathrm{~s}])$. Investigation of hot-streaks of our main interest here would be also subject to these challenges.

The main goal of this work is to investigate the combustor-turbine interactions specifically in terms of hot-streaks and to deliver encouraging CFD results using the OpenNCC, which is the publically available version of the National Combustion Code $(\mathrm{NCC})^{4}$ developed at NASA Glenn Research Center. OpenNCC uses unstructured meshes and has a massively parallel computing capability, with which we are successfully able to simulate many combustors related problems to support a variety of NASA projects. In this work, we investigate the flow fields inside the combustor and the first stage of HPT from the Energy Efficient Engine $\left(\mathrm{E}^{3}\right)$ program, ${ }^{5}$ excluding the rotor that requires the moving mesh type of approach to take into account the rotation of the blade. This simplification should not have much negative impact on accuracy in the prediction since the longitudinal waves, which significantly affect the velocity field (and temperature field), are mainly reflected by the first vane, so our simplified model should be able to capture the main effects of the presence of the turbine on the flow field in the combustor and obtain a realistic flow field at the combustor exit.

This paper is organized as follows: in Section 2, we briefly review the $\mathrm{E}^{3}$ combustor/HPT and explain the three different geometries of interest. In Section 3, we describe the physical model and the numerical approach including a summary of the boundary condition, operating condition, and the chemical mechanism. Results from the simulation studies are discussed in Section 4 and conclusions are made in Section 5.

\section{II. $\mathrm{E}^{3}$ Combustor and High Pressure Turbine}

The $\mathrm{E}^{3}$ combustor is the double-annular and compact combustor (See Fig. 1). The fuel injected from thirty fuel nozzles and the swirling air are efficiently mixed and combusted in a short distance. At a low power condition, only the outer dome is fueled, and a rich combustion zone is formed. At a high power condition, both domes are fueled and a large amount of airflow is introduced into the inner dome annulus, creating a very lean combustion zone. Large dilution holes at the center body and inner/outer liners are designed in such a way that the cold airflow immediately mixes with the hot product, suppressing the further NOx

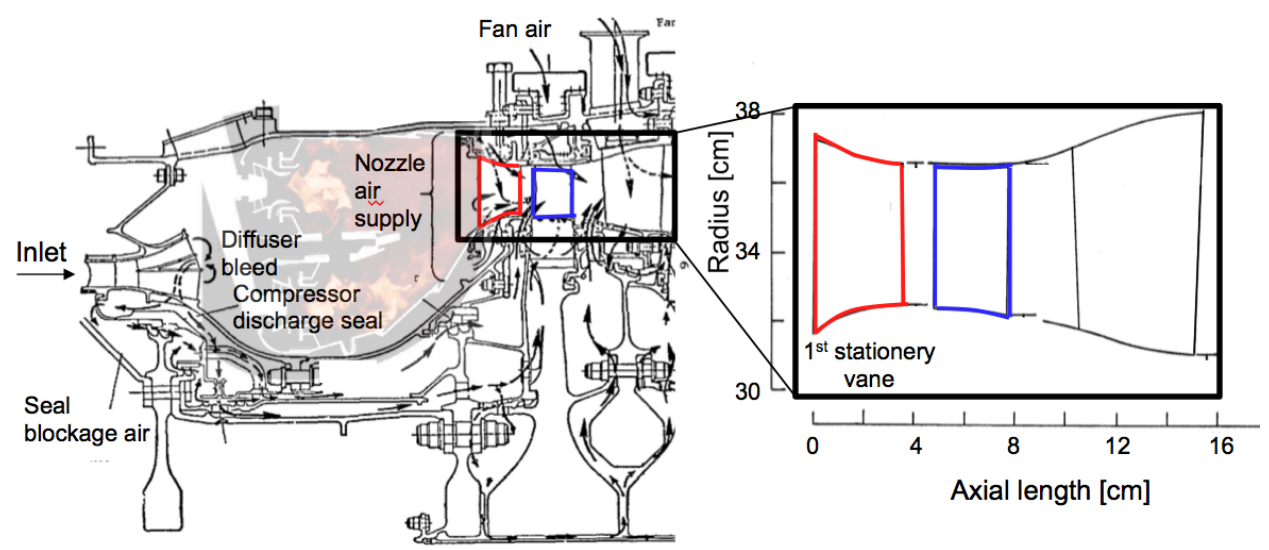

Figure 1. Cross section of the $\mathrm{E}^{3}$ combustor and $\mathrm{HPT}^{1,2}$ 

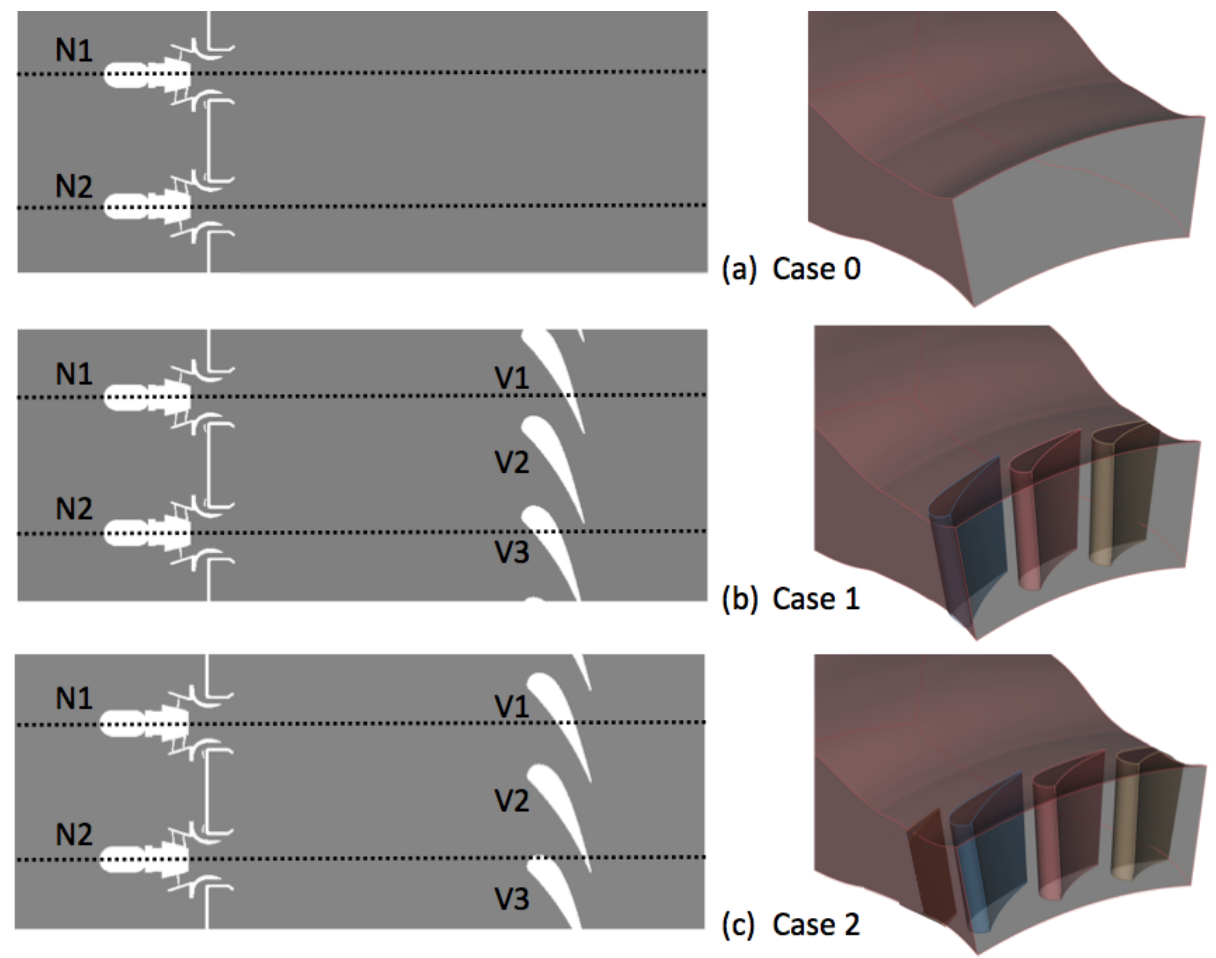

Figure 2. Three different geometries with/without the vane and different clocking, (left) viewing from casing toward hub and (right) viewing the combustor exit.

formation. The $\mathrm{E}^{3}$ combustor was intensively investigated in the mid-1970s and 1980s and set a historically important milestone toward more fuel efficient jet engines that meet the emission requirements. The relevant technologies that emerged from this program have since been widely used in current commercial engines. A detailed explanation of $\mathrm{E}^{3}$ can be found elsewhere. ${ }^{6}$

The high pressure turbine (HPT) for the GE $\mathrm{E}^{3}$ is a two-stage, low thru-flow design for moderate loading. As part of the programs, the vane configuration was studied based on the aerodynamic performance to determine the design point efficiency and to map the turbine over a large range of operating conditions. Another important component of HPT performance is how to design the flow-path (shape of the hub/case) inside the HPT. To this aim, the three-dimensional, radial equilibrium equations were solved for circumferentially averaged flow, taking into account the streamline slope, airfoil blockage, radial gradients of flow properties and curvature. The final design Mach number and flow angle at the exit of the first stator is about 0.8 and 75 degrees, respectively. The inclusion of cooling holes are critical to avoid any potential hardware damage, and hundreds of holes must be carefully located on the vane surface (especially at the stagnation point and at the pressure side) and the surface of the hub/case. To test the full scale design of the two-stage HPT fully cooled, the air turbine rig was constructed. A detailed description of the air turbine rig and the experimental data are provided in the NASA technical report ${ }^{1,2}$

A critical issue here is how to combine the two components of the combustor and the HPT. In other words, we have to decide a relative position of the stator with respect to the fuel nozzle, so-called "clocking". It is indeed important since the existence of the stator plays a role in blocking the hot combustion product passing the stator as well as the pressure oscillations generated by the combustor. As a result, the pressure inside the combustor is expected to increase and the characteristics of the combustion dynamics can change. These effects are related to each other in a complex manner. Although there are a number of experimental and numerical studies ${ }^{7-12}$ which have sought to ascertain the combustor-turbine interactions, we still have not achieved a complete understanding of how flow fields (including the hot-streaks) are affected by the effect of the presence of the stator and clocking. This study is a first step toward the ultimate objective of tightly-coupled unsteady simulations of combustor-turbine interactions for a realistic combustor and a turbine geometry. 
In this study, we consider three different geometries (Case 0, Case1, and Case 2), which are shown in Fig. 2, Case 0 does not include the vane, and the two other cases have the vane, but each has a different clocking. The difference of clocking between Case 1 and Case 2 is two degrees. (Note that in the actual experiment, there are 46 vanes in the first stage. However, for simplicity, we consider the case with 45 vanes for the full annular combustor). In these cases, some vanes are completely aligned with or off from the fuel nozzle. For instance, in Case 1, the middle vane (V2) is located between the fuel nozzles, but the leading edge (i.e., stagnation point) of the last vane (V3) is aligned with the fuel nozzle (N2). Recently, Koupper et $a l .{ }^{9}$ conducted a Large Eddy Simulation to investigate the combustor-turbine interactions for a Lean Burn chamber and was able to show that the different clocking indeed results in the different migrations of the hot-streaks around the vanes. Also, the presence of the two vanes at the combustor exit alters the radial and azimuthal mass flow distribution and the turbulence level. In their study, although the hot streaks are simply injected in front of the leading edge of the vane (e.g., the combustion model is not included), their work provides a physical insight into combustor-turbine interactions and shows the capability of the LES to model this kind of problem.

\section{Numerical Models}

In this section, the numerical setup and relevant physical models used in this study are briefly provided.

\section{A. Open National Combustion Code}

A brief explanation of OpenNCC is provided in this section. OpenNCC is the releasable version of the NCC, which has been continuously updated for more than two decades at NASA Glenn Research Center (GRC). It is a state-of-the-art code equipped with a comprehensive combustion model, a turbulence model (cubic non-linear $k-\epsilon$ model with the wall function), finite rate chemistry with turbulence chemistry interaction models, PDF transport model, ${ }^{13}$ Eddy-Breakup Model (EBU) ${ }^{14}$ and Linear-Eddy Model (LEM),${ }^{15,16}$ and spray model (Lagrangian liquid phase model). ${ }^{17,18}$ Many previous papers and presentations (e.g., ${ }^{4,19-24}$ ) have shown that OpenNCC (as well as NCC) has facilitated the combustion CFD in the development/design of the combustion technology at NASA-GRC. For the numerical and mesh capability, OpenNCC is designed for unstructured grids (i.e., any mix of three-dimensional elements: hexahedral and tetrahedral mesh), and

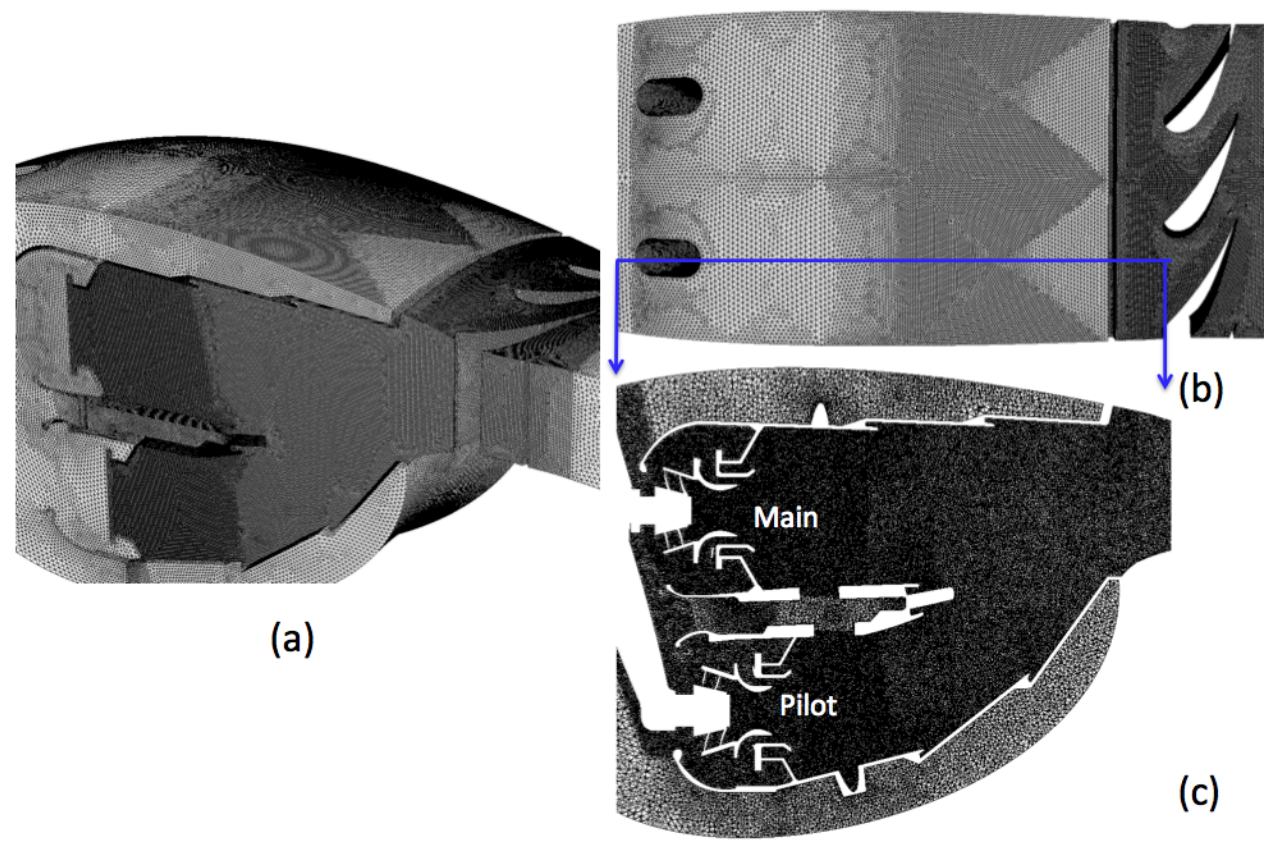

Figure 3. (a) Overview, (b) top view and (c) cross section of mesh of Case 1. 
Table 1. Spray model parameters.

\begin{tabular}{cccccc}
\hline Liquid component & $\mathrm{T}_{\text {spray }}[\mathrm{K}]$ & \# of holes & \# of stremas & SMDM $[\mu \mathrm{m}]$ & $\mathrm{v}_{\text {spray }}[\mathrm{m} / \mathrm{s}]$ \\
\hline $\mathrm{C}_{11} \mathrm{H}_{21}$ & 515 & 128 & 8 & 8.8 & 50 \\
\hline
\end{tabular}

Table 2. $\mathrm{E}^{3}$ experimental setup. 6

\begin{tabular}{c|ccccccc}
\hline & $\mathrm{P} 3[\mathrm{~atm}]$ & $\mathrm{T} 3[\mathrm{~K}]$ & $\mathrm{W} 3[\mathrm{~kg} / \mathrm{s}]$ & $\mathrm{Wf}_{\text {total }}[\mathrm{kg} / \mathrm{s}]$ & $\mathrm{f} / \mathrm{a}$ & $\mathrm{Wf}_{\text {pilot }} / \mathrm{Wf}_{\text {total }}$ & $\mathrm{T}_{\text {fuel }}[\mathrm{K}]$ \\
\hline SLTO & 2.52 & 720 & 0.26 & 0.00364 & 0.014 & 0.5 & 520 \\
\hline
\end{tabular}

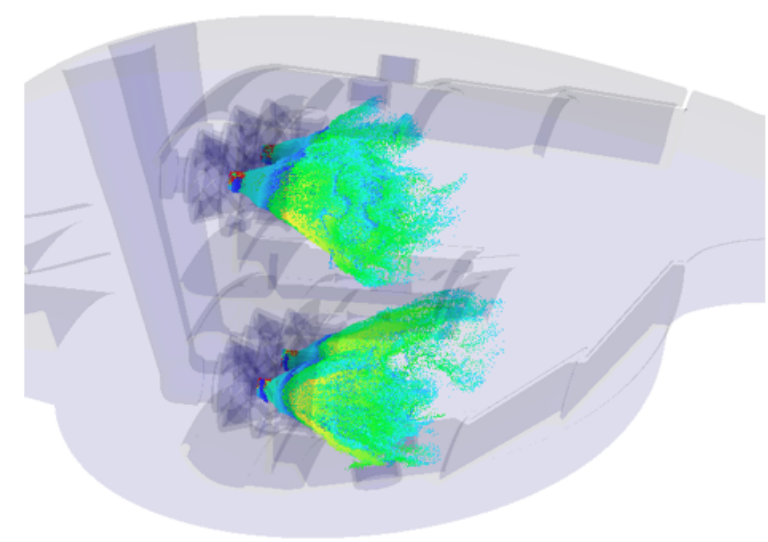

(a)

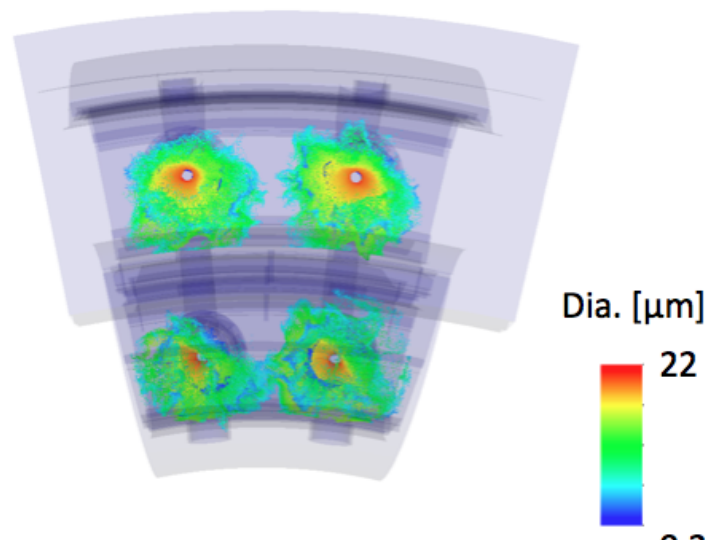

(b)

Figure 4. Instantaneous distribution of fuel-droplets colored by the diameter (red: large and blue: small) of Case 2.

massively parallel computing (with almost perfectly linear scalability is achieved for non-spray cases up to 4000 central processing units). In addition, the adaptive mesh refinement option is recently implemented. ${ }^{25}$ For low-speed flow, pre-conditioning is used for better convergence. Regarding the numerical method, a dual time-stepping procedure in which the solution implicitly advances in physical time and the explicit four-stage Runge-Kutta scheme is called in pseudo-time, is adopted. The transport equations are spatially discretized using a cell-centered finite-volume method. In this study, the $2^{\text {nd }}$ order $\mathrm{AUSM}^{+}$-up scheme is used to calculate the inviscid flux minimizing the numerical dissipation. Throughout this study, we turn on the preconditioning and use the minmod function as the limiter of the MUSCL scheme for the AUSM ${ }^{+}$-up scheme. For the turbulence model, the cubic non-linear $k-\epsilon$ model ${ }^{19}$ is used. Although a turbulence chemistry interaction could be important in modeling this type of combustor, we decided to use the laminar chemistry (i.e., no temperature fluctuation effect on the chemical reaction). In future works, we would like to turn on the turbulence chemistry interaction model and perform a sensitivity analysis of these models against our predictions.

\section{B. Reduced Chemical Mechanism: Jet-A/Air}

The flame dynamics and flame shape are the critical factors that determine the overall model accuracy. Therefore, peak heat release, flame speed, and equilibrium temperature/species need to be captured as precisely as possible given the chemical model. In general, two types of chemical model are commonly used in the context of Large Eddy Simulation in the gas-turbine community: reduced chemistry and tabulated chemistry. The first one is "reduced" from a large chemical mechanism, but it is still confirmed to have 


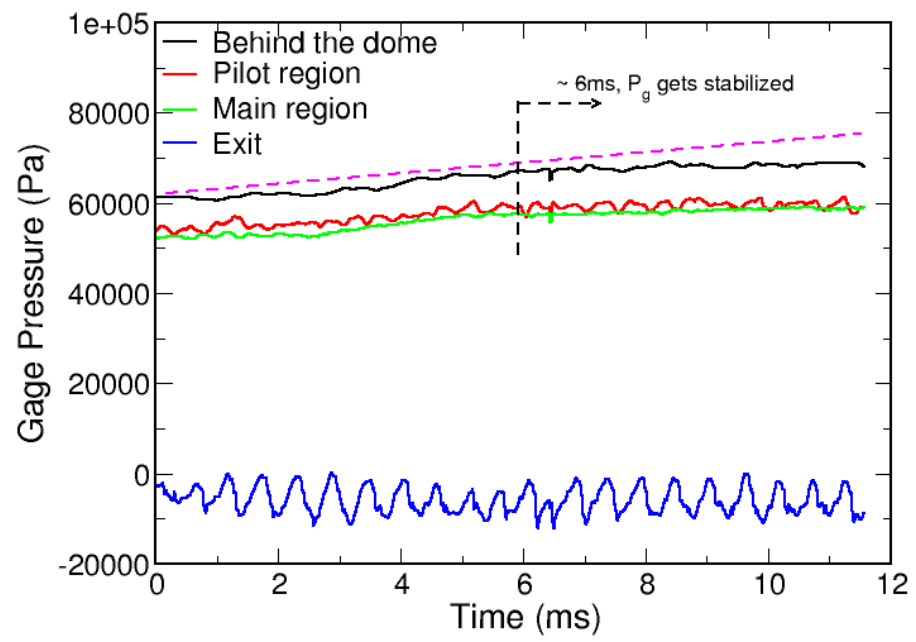

Figure 5. Gauge pressure histories at four different locations of Case 1.

captured the main quantities (e.g., flame speed, equilibrium temperature/species, autoignition, etc.). The second one relies on a tabulated description of the product based on the current species composition and thermodynamic state. The main drawback of this type of approach is having to be sensitive to the choice of the prototype flame in order to generate the tabulation. Since there are a wide variety type of combustion modes taking place within the combustor, a reduced chemistry is our preferred choice.

A reduced chemistry with modified rate coefficients for kerosene-air flames was recently developed by Centre Européen de Recherche et de Formation Avancée en Calcul Sceintifique (CREFACS). ${ }^{26}$ Under the restrictions of having a limited number of species and reaction steps, they successfully validated their model (two-step reaction with 5 species, $\mathrm{KERO}, \mathrm{O}_{2}, \mathrm{CO}, \mathrm{H}_{2} \mathrm{O}, \mathrm{CO}_{2}$ ) over a wide range of pressure, temperature and fuel-air ratio. In their mechanism, two following global reactions are proposed:

$$
\begin{aligned}
& \mathrm{KERO}+10 \mathrm{O}_{2} \rightarrow 10 \mathrm{CO}+10 \mathrm{H}_{2} \mathrm{O} \\
& \mathrm{CO}+0.5 \mathrm{O}_{2} \leftrightarrow \mathrm{CO}_{2}
\end{aligned}
$$

And then, the forward reaction rates of these global reactions are provided by:

$$
\begin{aligned}
& k_{f, 1}=A_{1} f_{1}(\phi) \exp \left(-E_{a, 1} / R T\right)[K E R O]^{n_{K E R O}}\left[O_{2}\right]^{n_{O_{2}, 1}} \\
& k_{f, 2}=A_{2} f_{2}(\phi) \exp \left(-E_{a, 2} / R T\right)[C O]^{n_{C O}}\left[O_{2}\right]^{n_{O_{2}, 2}}
\end{aligned}
$$

where $A_{i}(\mathrm{i}=1,2)$ and $E_{a, i}(\mathrm{i}=1,2)$ are the pre-exponential factors and the activation energies, and are set to be: $A_{1}=8.0 \times 10^{11}, A_{2}=4.5 \times 10^{10}, E_{a, 1}=41500$ and $E_{a, 2}=20000$, respectively. $n$ is the reaction exponent term: $n_{K E R O}=0.55, n_{O_{2}, 1}=0.9, n_{C O}=1.0$, and $n_{O_{2}, 2}=0.5$. Unlike a typical global mechanism, this mechanism needs the modification on the pre-exponential factor $\left(f_{1}\right.$ and $\left.f_{2}\right)$ based on the local equivalence ratio, $\phi$. The nonlinear functions of $f_{1}(\phi)$ and $f_{2}(\phi)$ are carefully formulated so that this simple, but highly capable reduced chemistry works well a large range of temperature $(300[\mathrm{~K}] \leqq \mathrm{T} \leqq 700[\mathrm{~K}])$, pressure $(1$ $[\mathrm{atm}] \leqq \mathrm{p} \leqq 12[\mathrm{~atm}])$ and the equivalence ratio $(0.6 \leqq \phi \leqq 2.0)$ with satisfactory accuracy.

\section{Spray Model (LSPRAY-V)}

OpenNCC is equipped with a Lagrangian spray model (LSPRAY-V $\left.{ }^{18}\right)$. The main feature of this model is to work in unstructured grids under the massively parallel computers, to take into account the multi-component liquid fuels with variable properties, and to consider a variety of vaporization and atomization, which enable the model to use over a wide range of applications (and operating conditions). For a primary atomization 


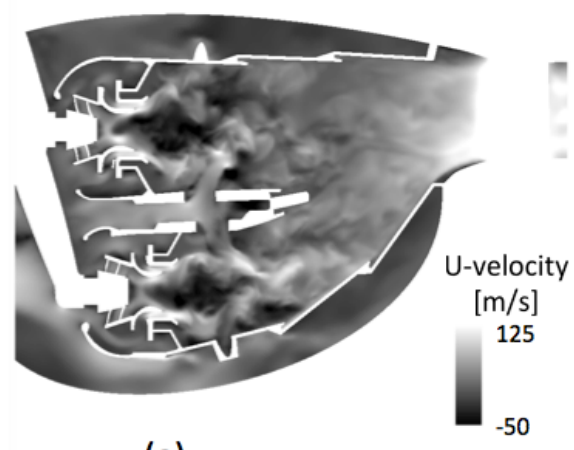

(a)

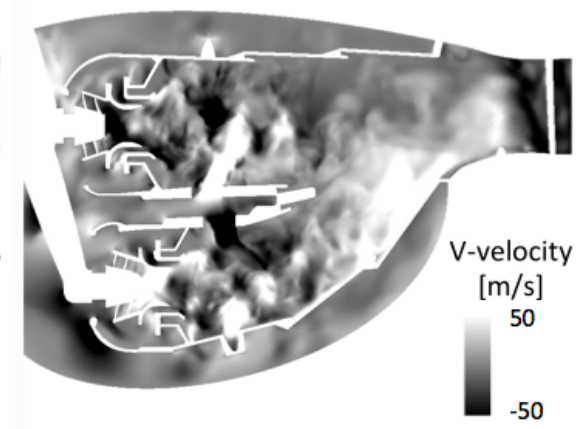

(b)
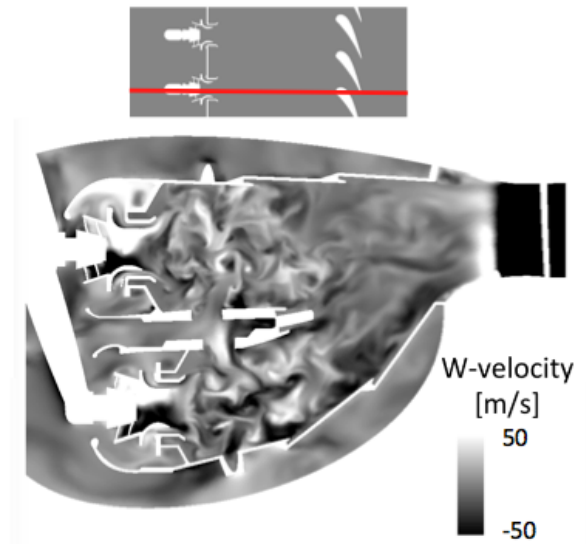

(c)

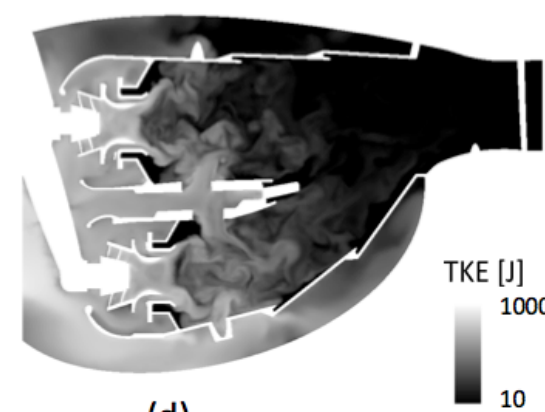

(d)

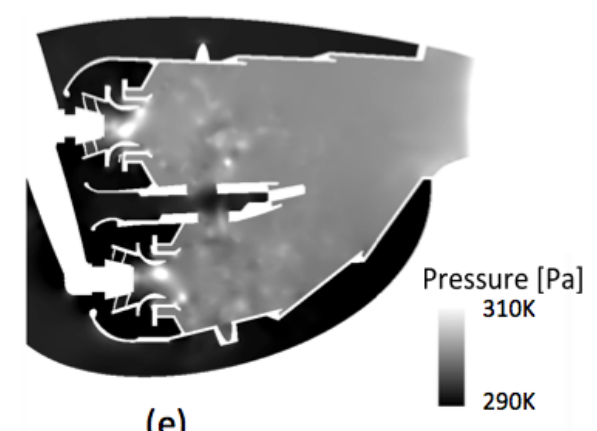

(e)

Figure 6. Instantaneous velocity, turbulence kinetic energy and pressure fields of Case 2 at $\mathrm{Z}=-0.032[\mathrm{~m}]$ (see the upper-right inserted figure).

model, we have the following four options: sheet breakup, air blast, blob jet, or Boundary-Layer Stripping. And, for a secondary droplet breakup model, there are three choices: Rayleigh-Taylor, Taylor Analogy Breakup, and Enhanced Taylor Analogy Breakup.

In this study, we use multi-point injections and stochastically inject the droplets mimicking a hole cone distribution. Initial droplet conditions are specified based on the experimental data when available. The summary of the initial conditions of the fuel-droplet specified by the input file of the spray model is shown in Table 1.

Figures 4 (a) and (b) show the instantaneous distribution of fuel-droplets colored by the diameter (red: large, and blue: small) of Case 2. The numbers of the holes and streams are large enough for the droplets to evenly spread after stochastically injected.

\section{Operating condition and Boundary Condition}

The $\mathrm{E}^{3}$ experimental setup is summarized in Table. 2 . The sea level takeoff condition (SLTO) is the most severe condition during the engine operation cycle. The pressured air ( $\mathrm{P} 3=2.52[\mathrm{~atm}])$ is introduced from the left boundary. The air goes around the diffuser splitter vane, and some portion of air is diffused into the strut cavity and routed through the hollow strut passage into the cooling circuit. Both the main and pilot domes are equally fueled $(0.00182[\mathrm{~kg} / \mathrm{s}])$. There are several cooling airflows at the outer/inner liners and the center body surface. We treat them as source/suction terms (i.e, no grids to resolve the cooling holes). More detailed information of the flow split is provided in Appendix. 


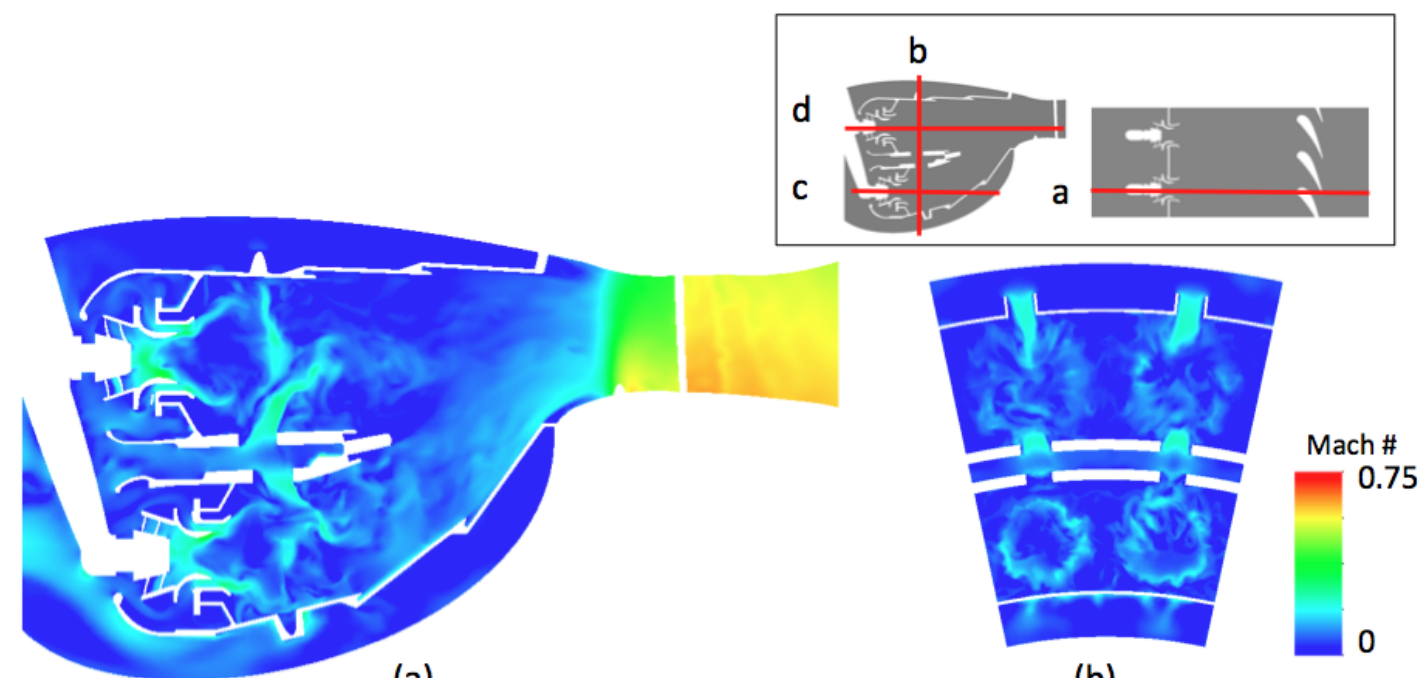

(a)

(b)

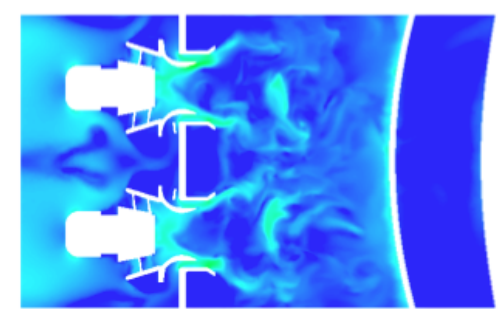

(c)

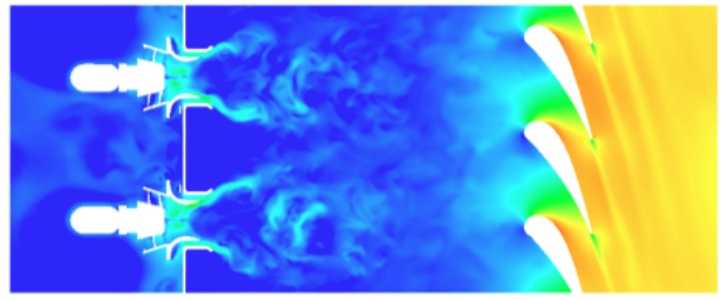

(d)

Figure 7. Instantaneous Mach number fields of Case 2 at the selected planes (see the upper-right inserted figure).

\section{Numerical Results}

For this study, we routinely use 1080 processors of Pleiades at NASA Advanced Supercomputing facilities. The tetrahedral mesh is generated by Cubit (see Fig. 3). The total mesh count is approximately 50 million elements for all three cases. The meshes inside the combustor are re-used, and only the meshes around the first stage vane are separately generated. This should minimize the grid effect while comparing the results among the three cases. As seen in Fig. 3, very fine and uniform grids are generated inside the combustor, especially within the vicinity of the fuel nozzles and dilution airflows, so the fuel-air mixing and flame structures should be adequately captured. However, we are aware that using tetrahedral mesh is numerically dissipative and not good at capturing the boundary layer.

For an unsteady calculation in this type of combustor, it is not trivial to decide whether solutions converge or not since there is a wide variety of length and velocity scales. Therefore, it is hard to define a "flowthrough time" that we commonly use for the convergence criteria to start taking the unsteady data. In this study, we carefully monitor the flow fields and thermodynamic state at many different locations inside the simulation domain and find that the gage pressure seems to be a good indicator for checking the convergence. As seen in Fig. 5, the gauge pressure increases in early stages of the calculation and subsequently reaches a quasi-steady state. All of the results shown in the following subsections are taken after the quasi-steady state is achieved. Mean solutions are constructed for averaging the data for at least 10 [ms].

\section{A. Instantaneous Flow Fields: Case 2}

In this subsection, we show some snapshots of the instantaneous flow fields obtained from Case 2. (The results from Case 0 and Case 1 are not shown here because the results are qualitatively similar to Case 2 ). The contours of u-velocity, v-velocity, w-velocity, turbulence kinetic energy (TKE) and gauge pressure 

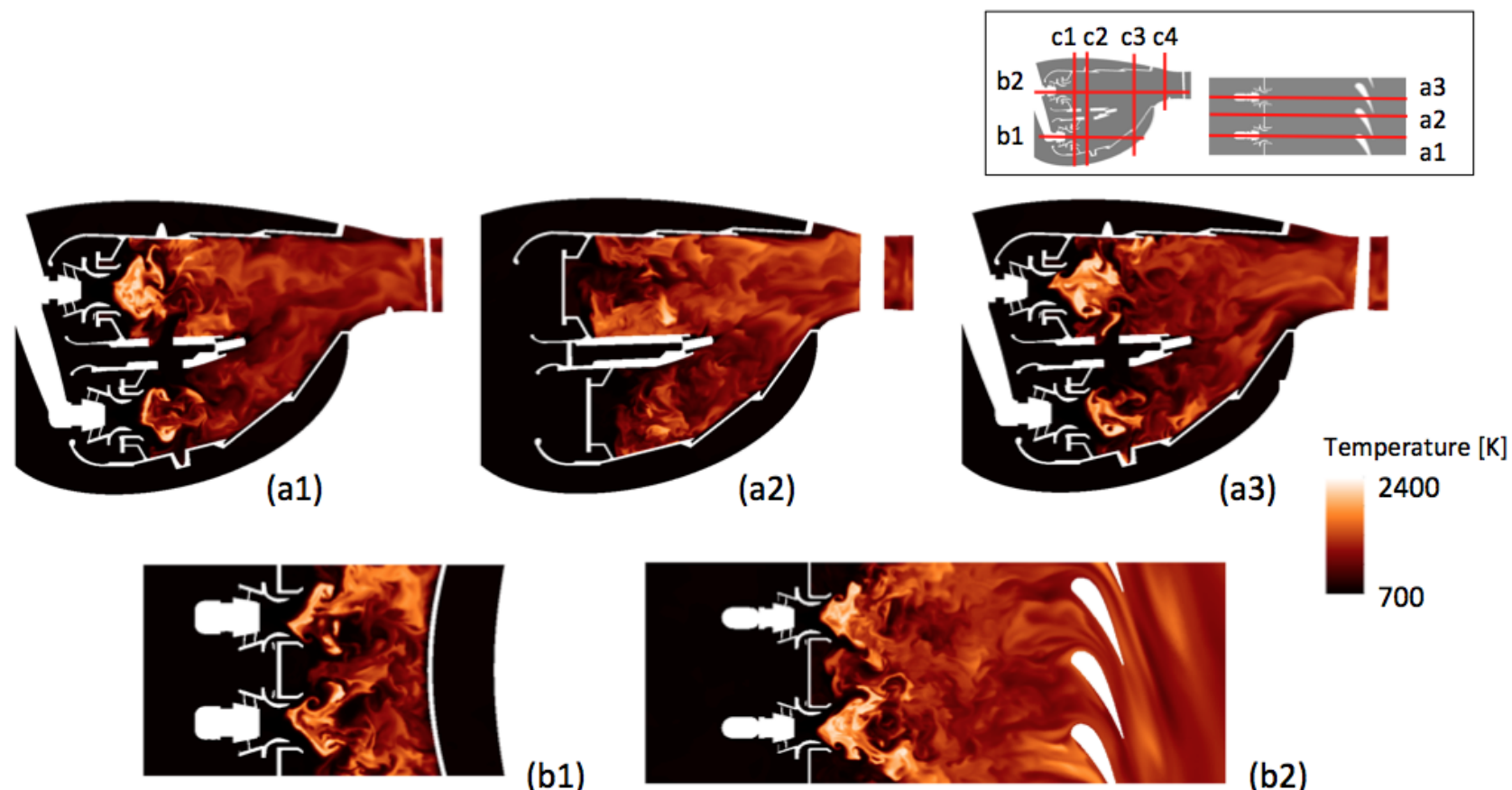

(b1)

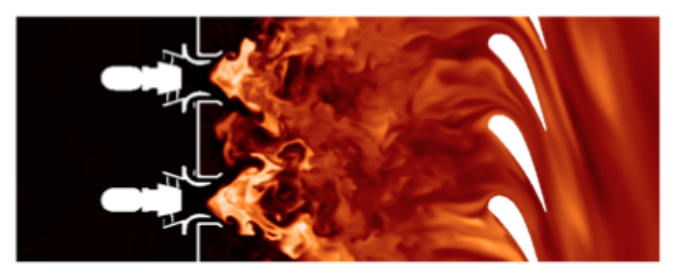

(a3)

2400
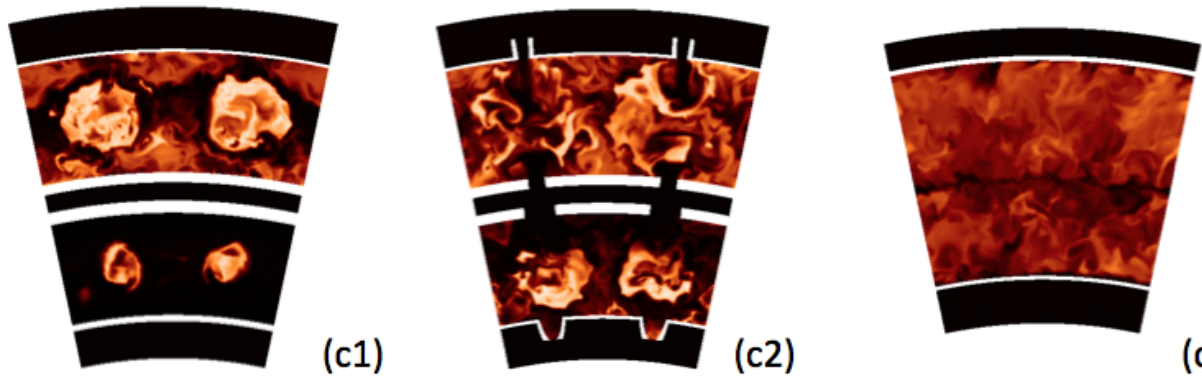

(b2)

Figure 8. Instantaneous temperature fields of Case 2 at the selected planes (see the upper-right inserted figure).

at the plane (Y=-0.032 [m]) crossing the fuel nozzle (N2) are shown in Figs. 6 (a)-(e). Gray scale is here used to make visible the fine structures of the flow fields. Firstly, a highly turbulent flow is observed inside the combustor, especially within the region where the dilution airflow and the highly-swirling flow meet and create eddies of many different length scales. Additionally, the breakdown of the large eddies into smaller ones occurs in the downstream region. However, it is also observed that some large scale eddies remain until the combustor exit, causing the significantly nonuniform flow fields there. This could have the potential to generate the hot-streaks, which would damage the stator surface. This will be discussed later.

In Figs. 6 (a)-(c), we observe that the highly-swirling flow is coming out of the main and pilot swirlers, generating a central recirculation zone (CRZ), which plays a critical role in holding the flame in this type of combustor. The maximum u-velocity (i.e., axial velocity) from the swirler reaches up to $120[\mathrm{~m} / \mathrm{s}]$, and then quickly attenuates by encountering the strong cross airflows from the dilution holes and the cooling airflows from liners. Unlike the $\mathrm{u}$-velocity and v-velocity profiles, the w-velocity profile looks more chaotic. This is in fact encouraging since our twenty-four degrees of the combustor geometry seems to capture the strong circumferential flow motions (Note that in our previous study using the twelve degrees geometry, ${ }^{24}$ we found that the circumferential variation in the flow structures is small). In the TKE profile (Fig. 6 (d)), it is seen that the TKE quickly decreases once the flow enters into the combustor. The reasons for this could be two-fold: the grid size in the combustor is small enough to resolve more turbulent energy (i.e., less unresolved turbulent energy), and the flow expands due to the rapid heat release from the combustion. It is shown in Fig. 6 (e) that there is high pressure behind the fuel domes and that the predicted pressure drop 


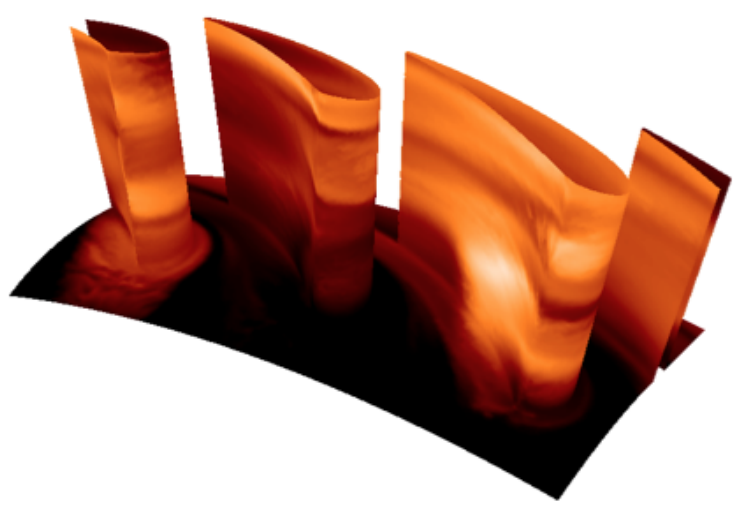

(a)

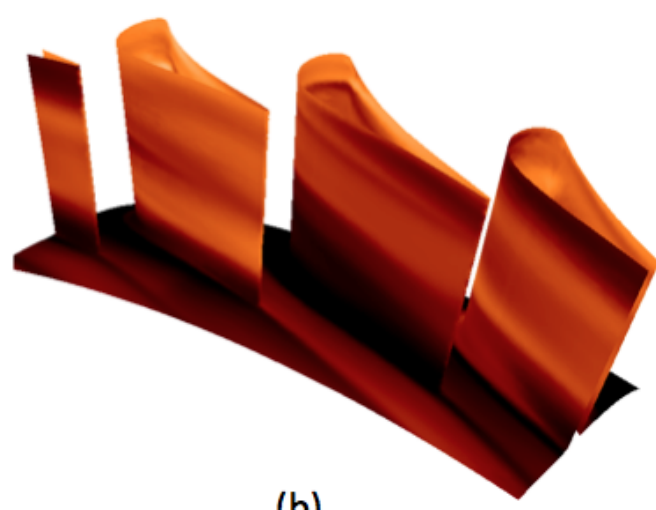

(b)
Temperature [K]

1600

1000

Figure 9. Instantaneous temperature profiles on the vane surface of Case 2, (a) pressure side and (b) suction side.

across the combustor liner is $4.5 \%$. The CRZ is often associated with the low pressure region in the vicinity of the fuel nozzle, the so-called precessing vortex core (PVC). The inherent unsteady feature of the PVC significantly impacts the combustion dynamics and emission. ${ }^{27,28}$ Since the droplets are injected at the fuel nozzle, the droplet distribution (see Fig. 4) is greatly influenced by the presence of the PVC, which has a negative impact on the combustion stability.

Figures 7 (a) -(d) show the instantaneous profiles of the Mach number of Case 2 at the selected planes indicated by the upper-right inserted figure. We observe that the flow accelerates near the vane and the maximum Mach number is about 0.75. Fig. 7 (b) illustrates that the strong swirling flow remains in a circular shape until it encounters the dilution airflow, at which point it breaks up, generating the small eddies downstream. As the flow approaches the combustor exit, the flow accelerates and subsequently the flow structures are elongated. Behind the vane, strong non-uniformity in the Mach number profile can be seen.

Instantaneous temperature profiles of Case 2 at the selected planes (see the upper-right inserted figure) are shown in Fig. 8. Figures 8 (a1)-(a3) show the temperature profiles at three different circumferential locations, $\mathrm{z}=-0.032[\mathrm{~m}]$ (passing the fuel nozzle, $\mathrm{N} 2$ ) , $\mathrm{z}=0.0[\mathrm{~m}]$ and $\mathrm{z}=0.032[\mathrm{~m}]$ (passing the fuel nozzle, N1). The hot product is trapped in the CRZs in front of each fuel nozzle, and helps fuel droplets evaporate and ignite. A relatively cold region exists between the fuel nozzles in the upstream region (See Fig. 8 (a2)). A large amount of cool air coming from the dilution holes quickly quenches the combustion (rich combustion is realized upstream) and the hot product goes around the dilution airflow. As a result, the temperature at the $\mathrm{z}=0.0[\mathrm{~m}]$ plane is higher than the one at $\mathrm{z}=-0.032[\mathrm{~m}]$ and $\mathrm{z}=0.032[\mathrm{~m}]$ planes (see Figs. 8 (b1) and (b2)). The temperature profiles at the four different cross-sections are shown in Figs. 8 (c1)-(c4). At $\mathrm{x}=0.195[\mathrm{~m}](\mathrm{c} 1)$, the circular shape of hot products held by the CRZ are located at the center of the fuel nozzles, and then break due to the dilution airflow at $\mathrm{x}=0.2[\mathrm{~m}](\mathrm{c} 2)$. Further downstream, $\mathrm{x}=0.25[\mathrm{~m}](\mathrm{c} 3)$, the well-mixed combustion products from the main and pilot are still separated by the center-body cooling air jets (A12-A14 in Table 5). At P40, $\mathrm{x}=0.32[\mathrm{~m}](\mathrm{c} 4)$, the temperature profile is not uniform in the circumferential direction as well as in the radial direction. The hot products are locally present, and the cooling air stays close to both the hub and the case. These instantaneous results indicate that the flow fields inside the combustor are highly non-uniform and that the non-uniformity remains well at the combustor exit, which is not preferred in the context of the hot-streaks. Instantaneous temperature fields on the vane surface of Case 2 are shown in Figs. 9 (a) pressure side and (b) suction side. In this calculation, the adiabatic condition is used and any cooling holes on the surface are not included. Therefore, the results should be interpolated with care. Locally hot spots (i.e., hot streaks) exist especially on the pressure side. Compared with the pressure side, a relatively cooler temperature distribution is observed on the suction side. It is found that there are many small-scale features on the vane surface, as indicated in Fig. 8 (c4). From these instantaneous results, we conclude that the temperature fields at P40 and in the vicinity of the 


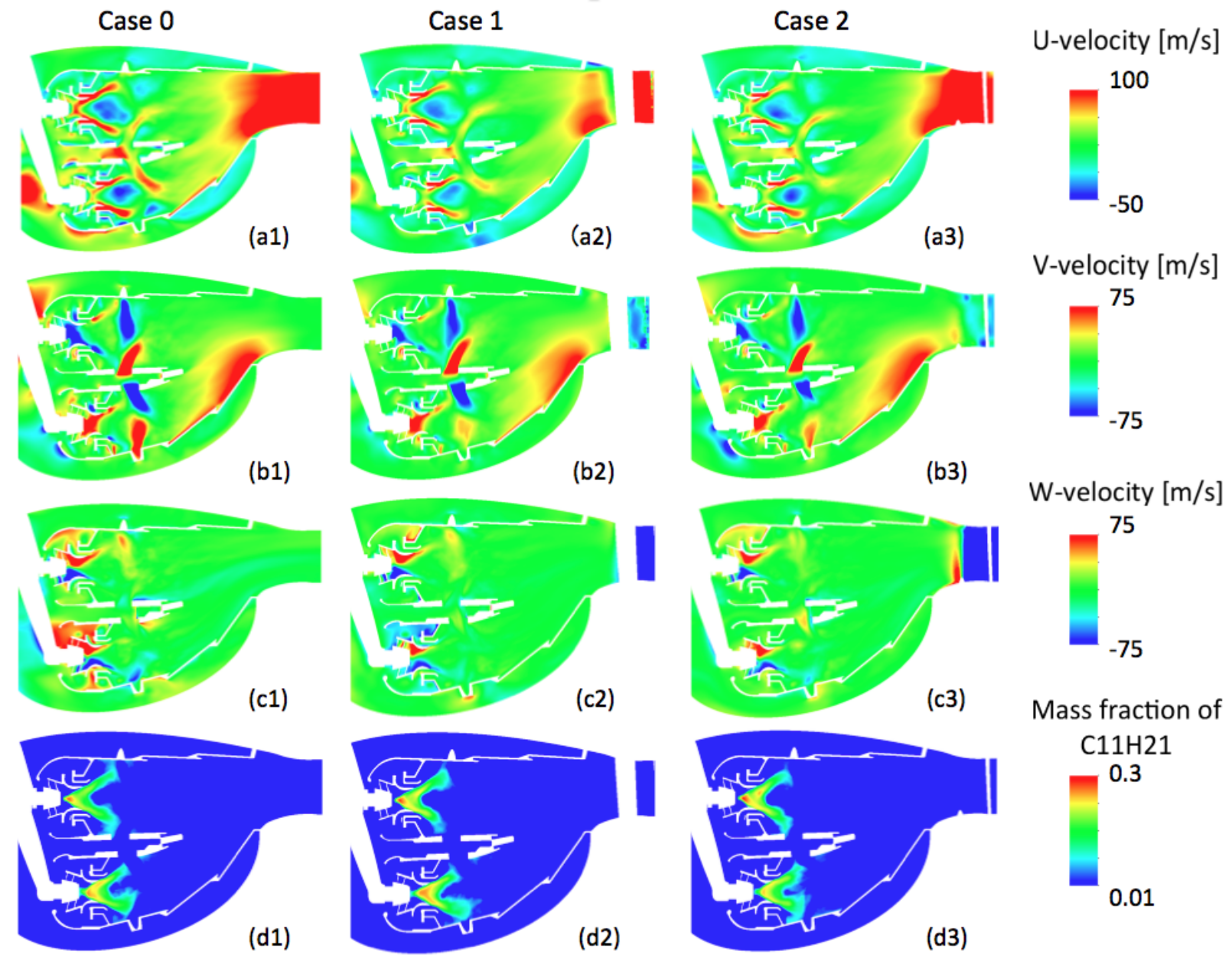

Figure 10. Comparison of time-averaged flow fields and mass fraction of $\mathrm{C}_{11} \mathrm{H}_{12}$ of Case 0 (left), Case 1 (mid.) and Case 2 (right) at $\mathrm{X}=\mathbf{- 0 . 0 3 2}[\mathrm{m}]$.

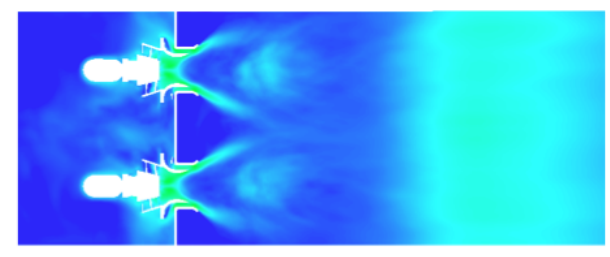

(a)

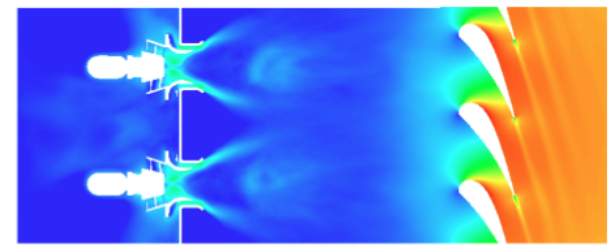

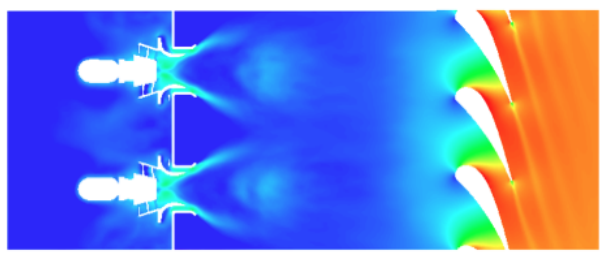

(b)

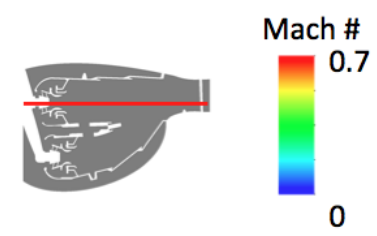

(c)

Figure 11. Comparison of time-averaged Mach number profiles of (a) Case 0, (b) Case 1 and (c) Case 2 at Y $=0.335[\mathrm{~m}]$. 

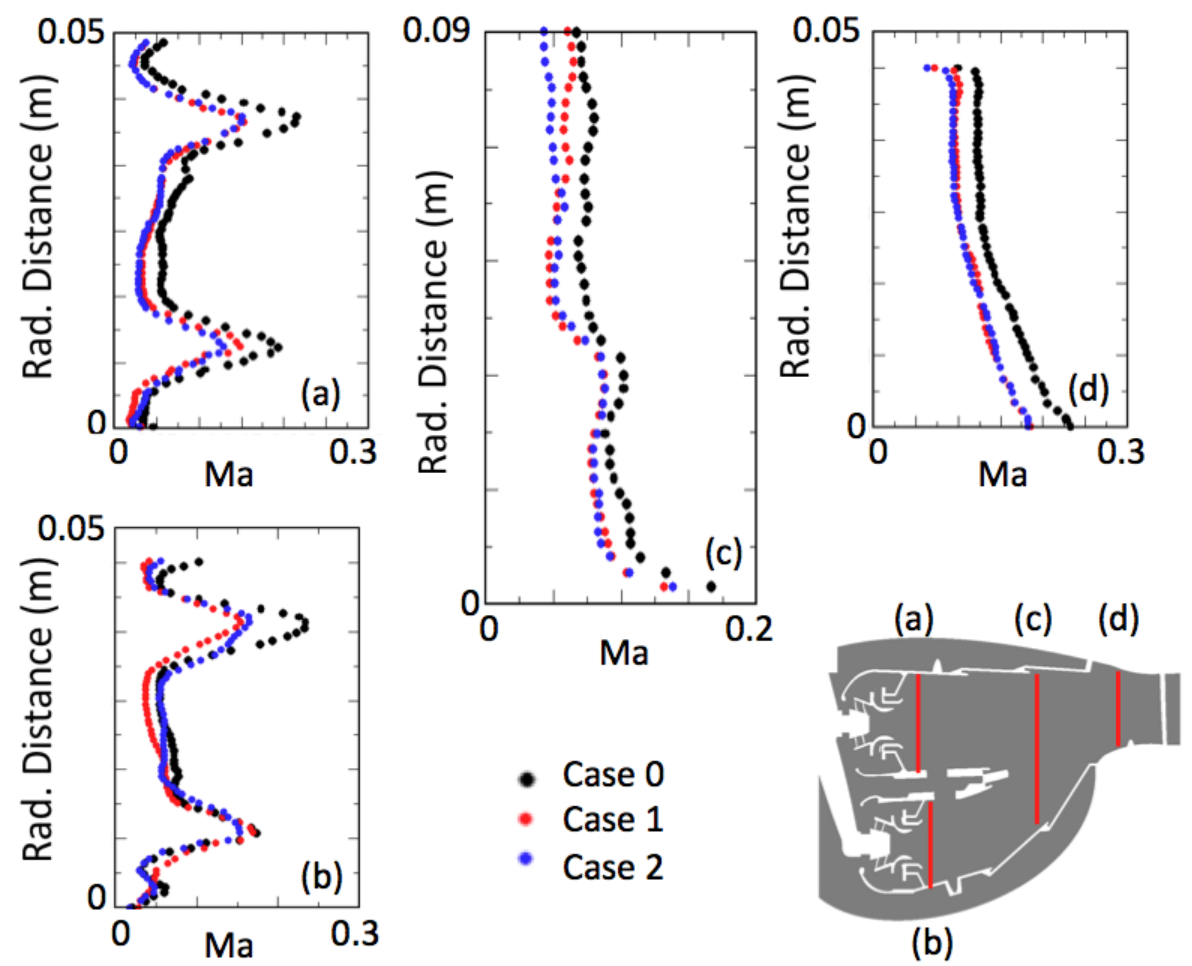

- Case 0

- Case 1

- Case 2

(b)

Figure 12. Time-averaged Mach number profiles at four different axial locations: (a) $X=0.18[\mathrm{~m}]$, (b) $X$ $=0.195[\mathrm{~m}],(\mathrm{c}) \mathrm{X}=0.26[\mathrm{~m}]$ and $\mathrm{X}=0.3[\mathrm{~m}]$.

first stage stator are not spatially uniform, and that the locally hot $(\sim 1600[\mathrm{~K}])$ and cool $(\sim 900-1000[\mathrm{~K}])$ spots co-exist, which can cause the severe thermal stress on the vane surface.

Next subsection, we see the time-averaged solutions of three cases.

\section{B. Time-Averaged Flow Fields: Case 0, Case 1 and Case 2}

In this subsection, we proceed with the analysis of time-averaged solutions of Case 0 , Case 1 and Case 2. In Figs. 10, a comparison of time-averaged u-velocity (a1)-(a3), v-velocity (b1)-(b3), w-velocity (c1)-(c3) and mass fraction of $\mathrm{C}_{11} \mathrm{H}_{21}$ is shown. All of the cases qualitatively capture the important features of the internal airflow inside the combustor in a similar way. However, we find that in Case 0, the magnitudes of the flow velocity of the swirling flow and the dilution airflow are larger than two other cases. As a result, the strength of the reverse flow inside the CRZ is stronger (slightly darker blue in the CRZ in Fig. 10(a1)). This should be related to the blocking effect of the existence of the vane at the combustor exit. In fact, the predicted pressure drop of Case 0 across the across the combustor liner is $4.8 \%$, which is $7 \%$ larger than those in Case 1 and Case 2. Stronger swirling flow and dilution airflow could have some impact on the overall flow fields and the characteristics of the combustion insider the combustor. While, there is a great similarity in the flow fields of Case 1 and Case 2, this same observation is not the same as seen in the work done by Roux et al. ${ }^{10}$ in which they show that the effect of the presence of the stator on the mean quantities is not significant in the primary zone. This different behavior could be due to the difference in combustors.

Figures 11 (a)-(c) show the contour of time-averaged Mach number at the $\mathrm{Y}=0.335[\mathrm{~m}]$ plane. As indicated from Fig. 10, Case 0 shows a slightly larger Mach number throughout the combustor, while Case 1 and Case 2 show very similar profiles. The difference between with/without the vane is significant, especially at the combustor exit. Without the vane, the flow gradually accelerates a bit further downstream of the exit. With the vane, the flow remains slow, but then quickly deaccelerates at the stagnation point or accelerates between the vanes. Nonuniformity caused by the boundary layer remains downstream of the vane. The maximum mach number is about 0.7 for both Case 1 and Case 2. Figures 12 show the Mach number profiles at four different axial locations, (a) $\mathrm{X}=0.18[\mathrm{~m}]$, (b) $\mathrm{X}=0.195[\mathrm{~m}]$, (c) $\mathrm{X}=0.26[\mathrm{~m}]$ and $\mathrm{X}=0.3[\mathrm{~m}]$. The 

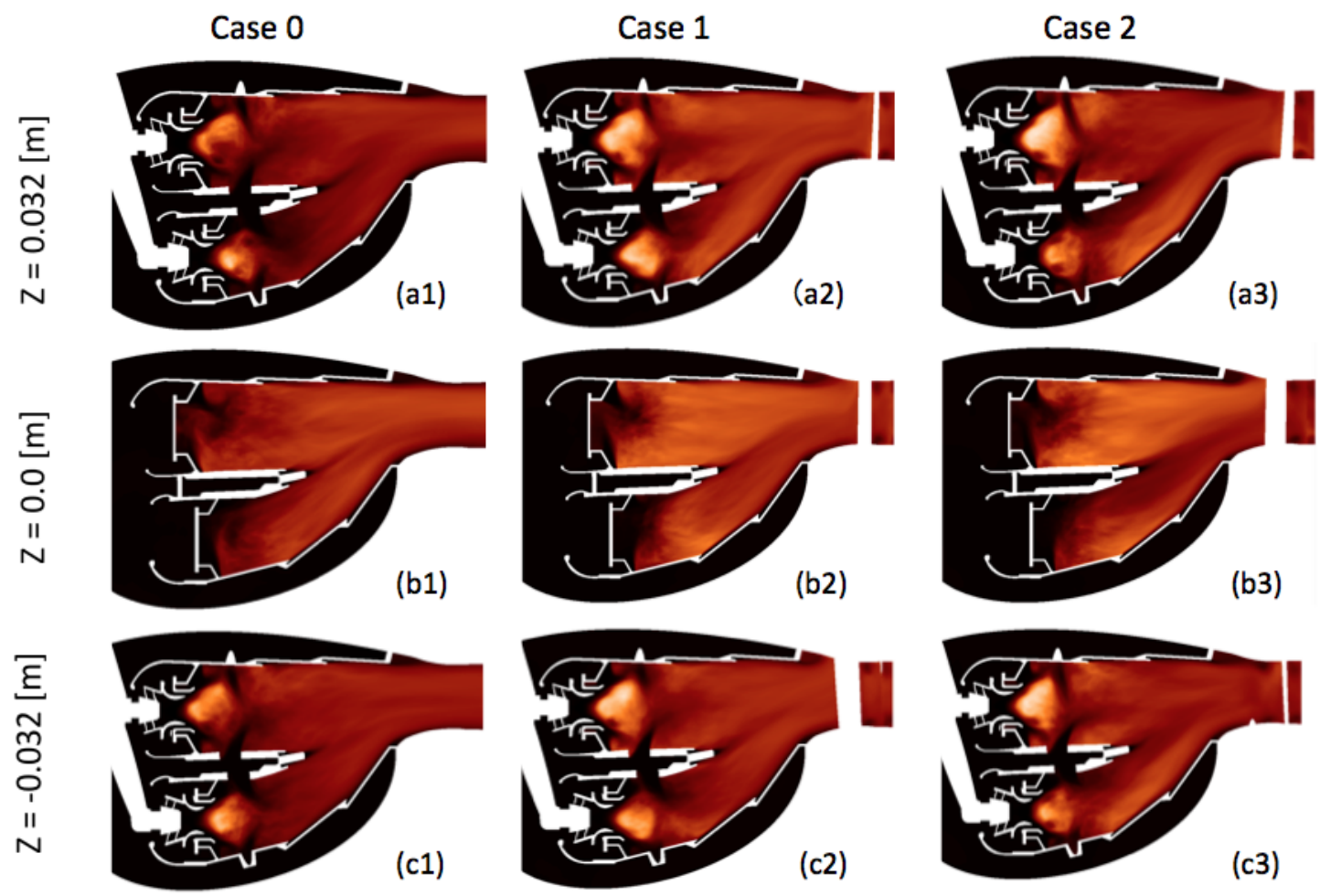

Temperature $[\mathrm{K}]$

2200

700

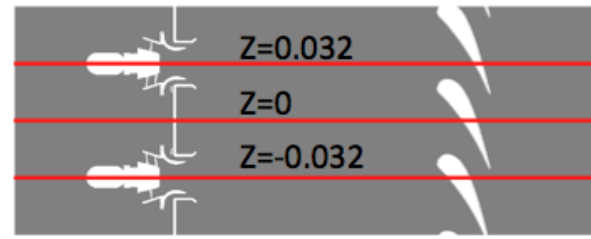

Figure 13. Comparison of time-averaged temperature fields of Case 0 (left), Case 1 (mid.) and Case 2 (right) at three different circumferential locations, $\mathrm{Z}=-0.032[\mathrm{~m}], \mathrm{Z}=0.0[\mathrm{~m}]$ and $\mathrm{Z}=0.032[\mathrm{~m}]$.

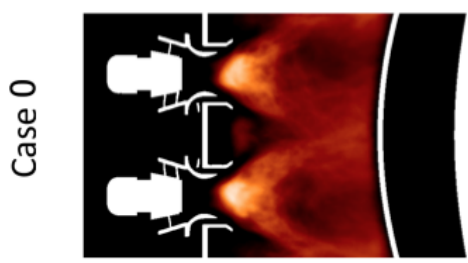

(a1)

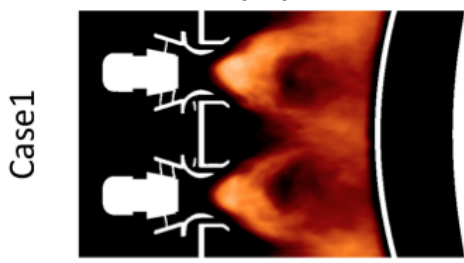

(a2)

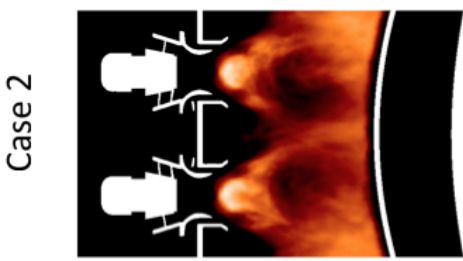

(a3)

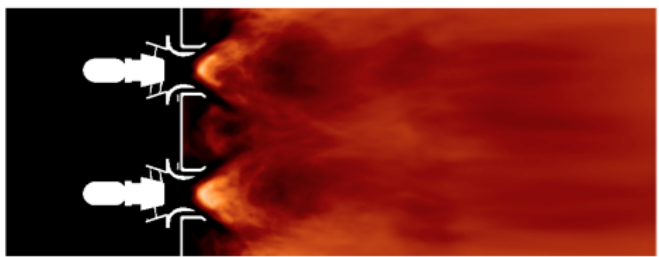

(b1)

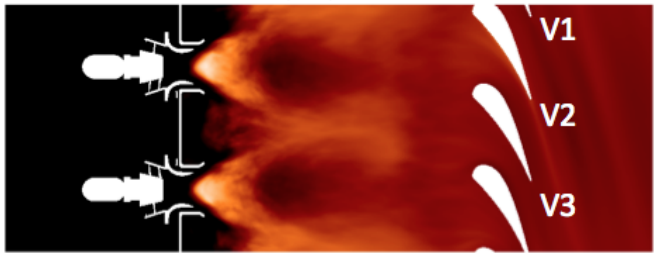

(b2)

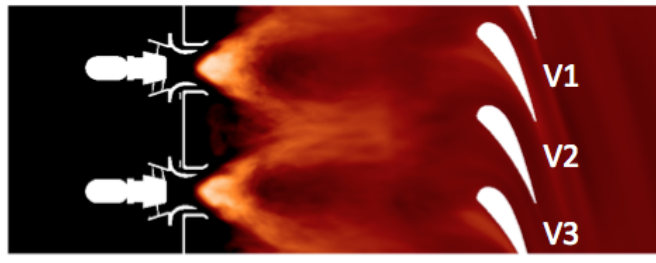

(b3)

Figure 14. Comparison of time-averaged temperatuße fields of Case 0 (top), Case 1 (mid.) and Case 2 (bot.) at $\mathrm{Y}=0.26[\mathrm{~m}]$ (left) and $\mathrm{Y}=\mathbf{0 . 3 3 5}[\mathrm{m}]$ (right). 


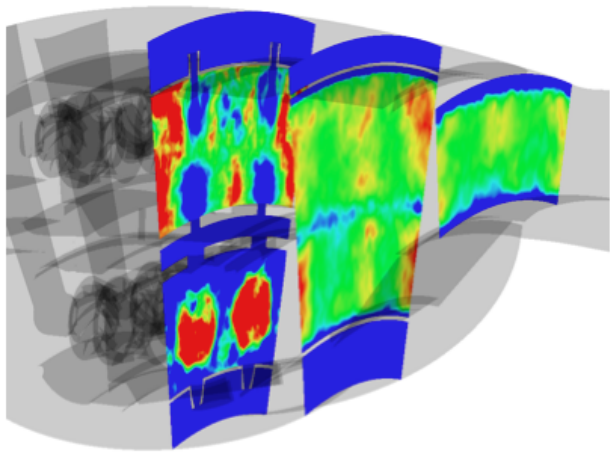

(a)

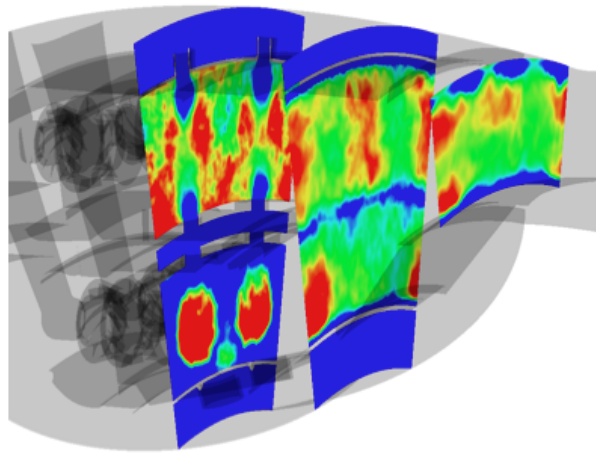

(b)

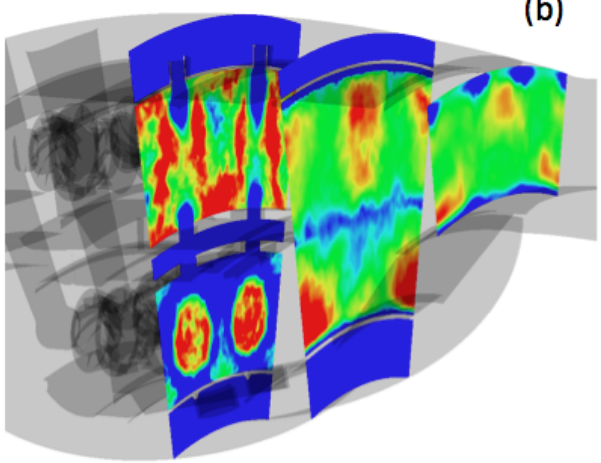

Temperature

$[\mathrm{K}]$

1600

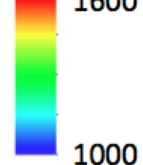

(c)

Figure 15. Comparison of time-averaged temperature fields of (a) Case 0, (b) Case 1 and (c) Case 2 at $\mathrm{X}=$ $0.2[\mathrm{~m}], 0.26[\mathrm{~m}]$ and $0.32[\mathrm{~m}](\mathrm{P} 40)$.

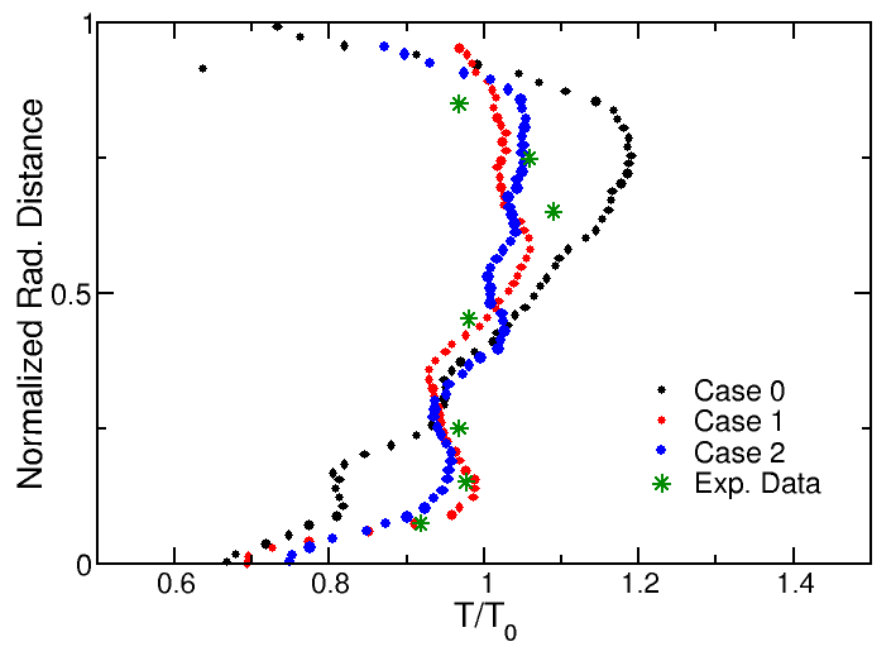

Figure 16. Circumferentially time-averaged temperature profiles at P40 of Case 1-3 with the experimental data.

bimodal distribution related to the swirling flow is shown in Figs. 12(a) and (b). We observe that Case 0 (black circle) indeed has a stronger swirling flow up to $30 \%$. This difference remains further downstream, whereas Case 1 and Case 2 show relatively similar results at all axial locations.

Comparison of time-averaged flow fields for Case 0, Case 1 and Case 2 at the three different circumferencial 

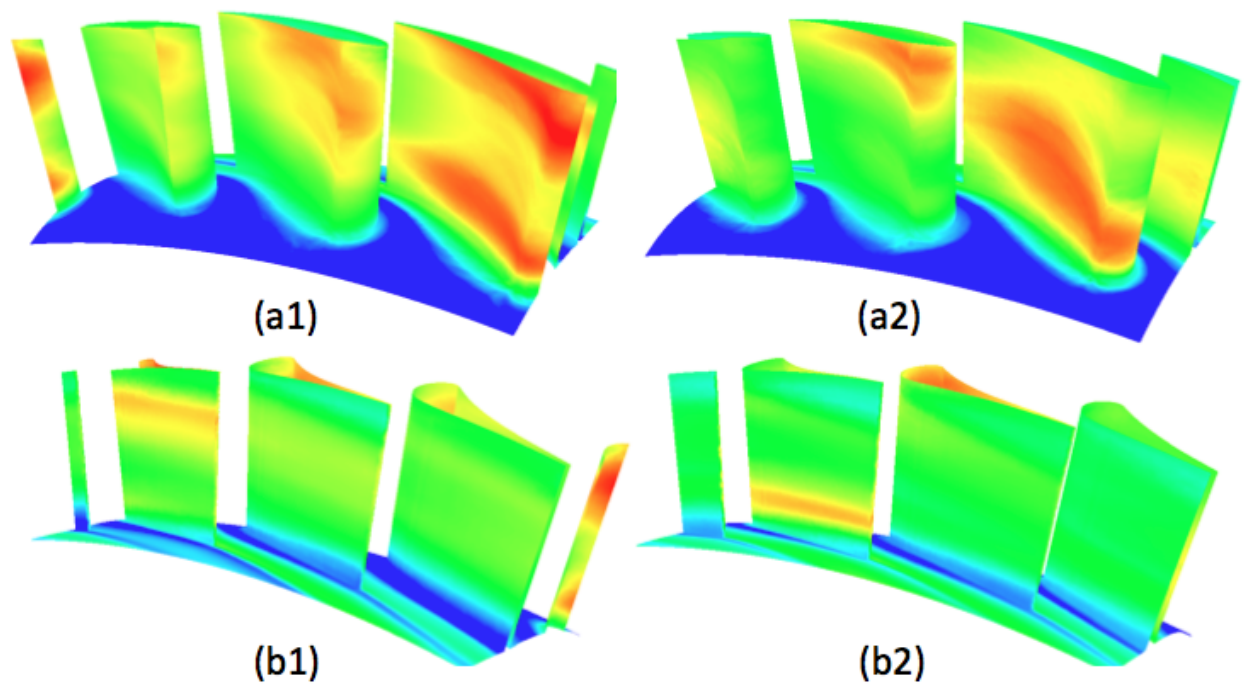

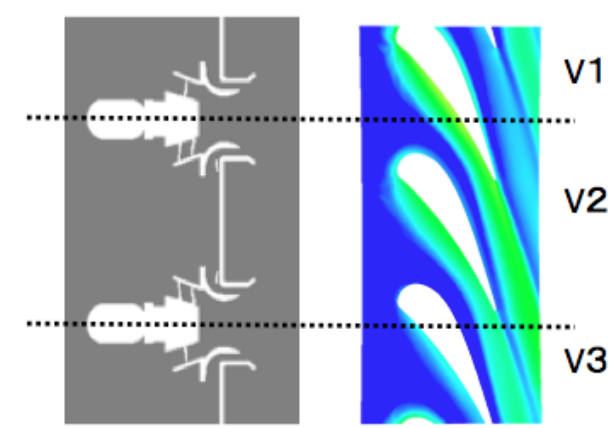

(c1)

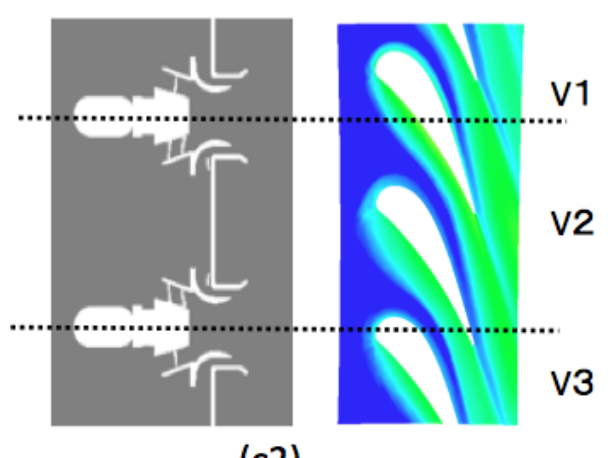

(c2)

Figure 17. Time-averaged temperature profiles on the first stage vane surface of Case 1 (left) and Case 2 (right), pressure side (top), suction side (mid.) and hub (bot.).

and two different radial locations is shown in Figs. 13 and Figs. 14. We observe the hot products are captured in the CRZs of the pilot and main, and then the cool dilution airflows enter the primary zone. It is seen that a slightly higher temperature region exits in the wake of the dilution airflow. This could be a problematic region in terms of NOx formation because of the hot and slow-moving flow. ${ }^{29}$ The cooling flow jets coming from the center-body (A12-A14 in Table 5) separate the two hot products from the main and pilot up to the combustor exit. Also, the hot product goes around the dilution airflows and stays between the nozzles (see Figs. 14). It is found that the overall temperature in Case 0 is slightly lower compared with Case 1 and Case 2.

This could be related to the stronger swirling flow and dilution airflow, which enhances mixing and reduces the flow resident time. Case 1 and Case 2 show similar temperature contours at these selected planes. However, some of the effects of clocking on the temperature field can be seen in Figs. 15 (a)-(c), in which the time-averaged temperature fields at the different axial locations are shown. The color map has been carefully chosen in order to enhance the temperature differences, especially between Case 1 and Case 2 . At the middle plane $(\mathrm{X}=0.26[\mathrm{~m}]$ ), all case shows five distinct hot regions (two in the bottom part (pilot) and three in the top part (main)). Note that because of a periodic boundary condition, two of them are connected to each other. These are related to the wake regions of the dilution airflows. Interestingly, in the bottom part, there is a hot region missing at the middle of the circumferential location. Also, the two hot regions in the top parts of Case 1 (See Fig. 15(b)) are slightly hotter than the ones in Case 2. Finally, at P40 (far-right plane), we observe that five distinct hot regions remain in Case 1, but only three remain in Case 2. The temperature of these three regions are slightly lower than the temperature of the five regions in Case 1. As will be shown later, this can be attributed to the fact that Case 2 shows more unsteady motions at the combustor exit (i.e., better mixing). 


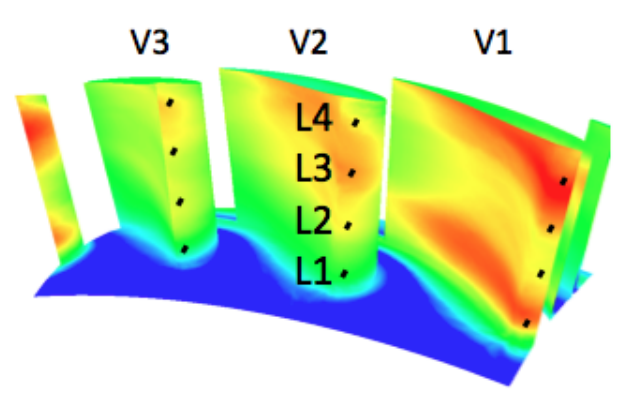

(a)

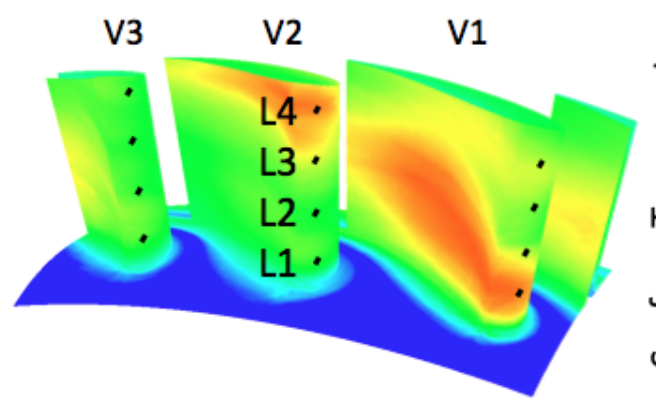

(b)

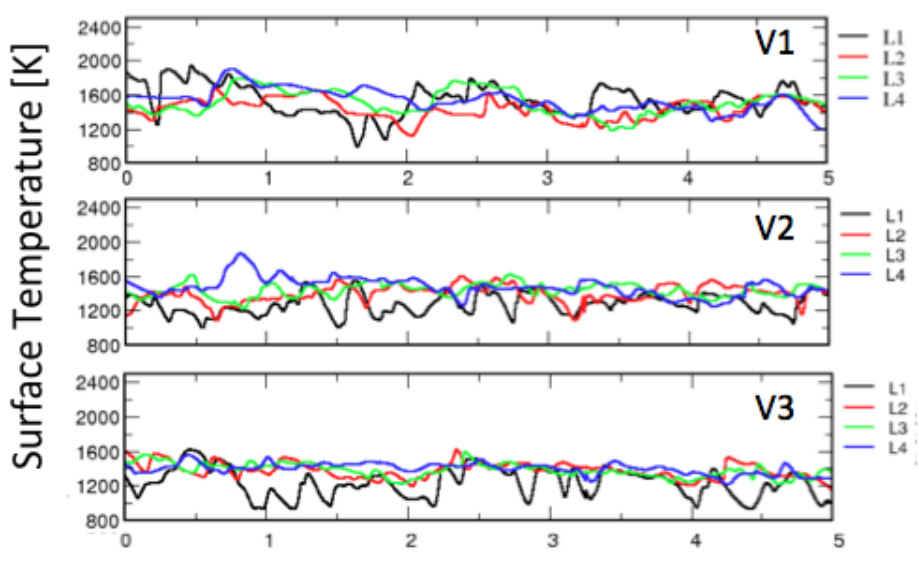

Time $[\mathrm{ms}]$

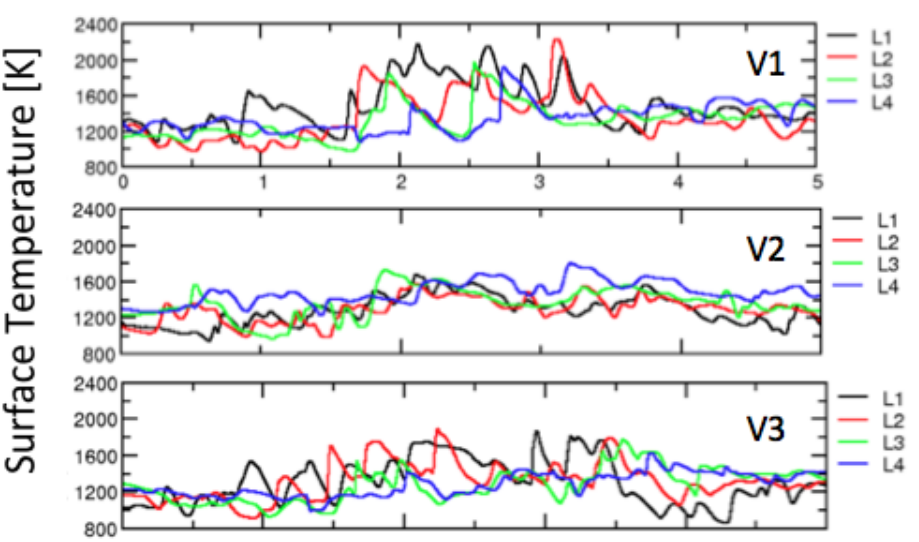

Time $[\mathrm{ms}]$

Figure 18. Time-histories of surface temperature of V1, V2 and V3, (a) Case 1 and (b) Case 2.

The circumferentially averaged normalized temperature profiles at $\mathrm{P} 40$ for all three cases and the experimental data are shown in Fig. 16. Here, $T_{0}$ is the reference temperature averaged over the surface at P40. Overall, we see good agreement with the experimental data. (Note that although we use the same operating conditions, we do not explicitly model the cooling air holes and assume the SMDM of the fuel droplet. Therefore, our results should be interpreted with care).

\section{Surface Temperature Fields on the first Stage Vane: Case 1 and Case 2}

In this subsection, we investigate the time-averaged profiles and time-histories of surface temperature at the first stage vane of Case 1 and Case 2 .

Figure 17 shows the time-averaged surface temperature profiles (a1)-(a2) at the pressure side, (b1)-(b2) at the suction side, and (c1)-(c2) at the hub of Case 1 and Case 2. The color map has been carefully chosen in order to enhance the temperature difference between Case 1 and Case 2. In Fig. 17 (a1), there are two hot streaks $(\sim 1600[\mathrm{~K}])$ located at the far-right vane $(\mathrm{V} 1)$, and these spots elongate on the pressure side. At the middle vane (V2), there is one hot streak near the case, but it is not as hot as the ones on V1. We find that the far-left vane (V3) is relatively cooler. For Case 2 (Fig. 17 (a2)), we see similar results in the sense that there are hot streaks on V1 and V2, but not in V3. Interestingly, there is only one hot streak on V1. Also, the temperature of these hot streaks $(\sim 1450[\mathrm{~K}])$ is not as high as the ones in Case 1. In fact, the locations of these hot streaks are closely related to the temperature profiles at P40 shown in Figs 15. On the suction side (Figs. 17 (b1) and (b2)), we observe much cooler temperature profiles compared with 
Table 3. Mean and standard deviation of temperature at the vane surface of Case 1.

\begin{tabular}{ccccccc}
\hline \hline & L1 $($ mean/SD) & L2 (mean/SD) & L3 (mean/SD) & L4 (mean/SD) & Mean T [K] & Stad. dev. (SD) [K] \\
\hline V1 & $1619 / 274$ & $1445 / 115$ & $1513 / 132$ & $1512 / 138$ & 1522 & 176 \\
V2 & $1304 / 134$ & $1381 / 111$ & $1431 / 81$ & $1475 / 104$ & 1397 & 109 \\
V3 & $1247 / 174$ & $1372 / 90$ & $1375 / 75$ & $1396 / 65$ & 1347 & 109 \\
\hline \hline
\end{tabular}

Table 4. Mean and standard deviation of temperature at the vane surface of Case 2

\begin{tabular}{ccccccc}
\hline \hline & L1 $($ mean/SD) & L2 $($ mean/SD) & L3 (mean/SD) & L4 (mean/SD) & Mean T $[\mathrm{K}]$ & Stad. dev. (SD) [K] \\
\hline V1 & $1408 / 238$ & $1294 / 237$ & $1303 / 183$ & $1356 / 143$ & 1340 & 200 \\
V2 & $1215 / 134$ & $1240 / 111$ & $1324 / 81$ & $1433 / 137$ & 1303 & 148 \\
V3 & $1257 / 274$ & $1284 / 115$ & $1277 / 132$ & $1297 / 138$ & 1278 & 167 \\
\hline \hline
\end{tabular}

the one on the pressure side. One belt-like hot temperature distribution appears on V1 (for both Case 1 and Case 2), but the temperature is less than $1350[\mathrm{~K}]$. We may conclude from this that the pressure side is much hotter than the suction side, which is consistent with past numerous studies (e.q. ${ }^{9,12}$ ). On the hub, both cases shows relatively similar results. However, there is a cold flow path between V1 and V2 in Fig. 17 (c1), which does not exit in Fig. 17 (c2). This should be attributed to the difference in clocking.

We now turn our attention to the unsteady features of the temperature profiles at the stagnation points of the three vanes that are subject to severe thermal stress. Figures 18 (a) and (b) show the time-histories of the surface temperatures of V1, V2 and V3 at four different radial locations (L1-L4). It is observed that the surface temperature significantly varies with time, reflecting the strong unsteady nature of the turbulent flow. Generally speaking, at L2 and L3 (the middle locations of the vane), temporal variations of the temperature are relatively small compared with those at L1 and L4. More importantly, Case 2 (Fig.18(b)) seems to show more temporal variation than Case 1. This observation is seen in other time segments (not shown here). Although the time-averaged surface temperature of Case 2 is lower than that of Case 1 , we find that the temporal variation of temperature is larger in Case 2. The qualitative comparison between Case 1 and Case 2 of mean temperature and standard deviation (SD) at each location is shown in Table 3 (Case 1) and Table 4 (Case 2). For all of the vanes, Case 2 shows larger values of SD, with lower mean temperatures. This may indicate that a different clocking alters the flow (temperature) pattern as well as combustion dynamics.

\section{Conclusions}

In this paper, we have investigated the $\mathrm{E}^{3}$ combustor using the OpenNCC developed at NASA Glenn Research Center. The three different geometries, without the vane and with the vane of two different clockings, are considered. Our numerical results show that the presence of the vane at the combustor exit increases the pressure inside the combustor (decreases the pressure drop across the liners), resulting in weaker swirling flows and dilution airflows. This blocking effect causes up to a $30 \%$ and $20 \%$ difference in Mach number near the fuel nozzle and the combustor exit, respectively. The effect of clocking is not significant in the flow fields inside the combustor and temperature fields in the primary zone. However, it indeed affects the distribution of the hot streaks at the first stage vane surface as well as P40. In addition, one case shows stronger temperature variation with time, but cooler. Also, our results show that the temperature field on the pressure side is much hotter than on the suction side. Future works will focus on the comparison of turbulence chemistry interaction models. 


\section{Acknowledgments}

This work was sponsored by the National Aeronautics and Space Administration's Transformational Tools and Technologies project. The authors would like to thank Christopher Heath, Thomas Wey, Tsan-Hsing Shih, Clarence Chang, and Kumud Ajmani for their assistance in preparing and running the simulations. The simulations were conducted on the NASA Advanced Supercomputing (NAS) Pleiades computer cluster. Grid generation was conducted with Cubit (provided by Sandia National Laboratories) and flow visualization was conducted with Visit (provided by Lawrence Livermore National Laboratories), respectively.

\section{References}

${ }^{1}$ Halila, E. E., Lenahan, D. T., and Thomas, T. T., "Energy Efficent Engine High Pressure Turbine Test Hardware Detailed Design Report," No. NASA/CR-1982-167955, 1982.

${ }^{2}$ Timko, L. P., "Energy Efficent Engine High Pressure Turbine Component Test Performance Report," No. NASA/CR$168289,1984$.

${ }^{3}$ Ames, A. A., "The influence of large-scale high intensity turbulence on vane heat transfer," Journal of Turbomachinery, Vol. 119, 1997, pp. 23-30.

${ }^{4}$ Stubbs, R. and Liu, N.-S., "Preview of the National Combustion Code," 33rd AIAA Joint Propulsion Conference, No. AIAA 1997-3114, Seattle, WA, July 1997.

${ }^{5}$ Ciepluch, C. C., Davis, D. Y., and Gray, D. E., "Results of NASA's Energy Efficient Engine Program," Journal of Propulsion and Power, Vol. 3, 1987.

${ }^{6}$ Burrus, D. L., Chahrour, C. A., Foltz, H. L., Sabia, P. E., Seto, S. P., and Taylor, J. R., "Energy Efficent Engine Combustor Test Hardware Detailed Design Report," No. NASA/CR-1984-168301, 1984.

${ }^{7}$ Dorney, D., Gundy-Burlet, K., and Sondak, D., "A Survey Of Hot Streak Experiments And Simulations," International Journal of Turbo and Jet Engines, Vol. 16, 1999, pp. 1-15.

${ }^{8}$ Murari, S., Sathish, S., Shraman, G., and Liu, J., "CFD Aerodynamic preformance validation of a two-stage high pressue turbine," ASME Turbo Expo 2011, No. GT2011-45569, Vancouver, Canada, June 610, 2011.

${ }^{9}$ Koupper, C., Bonneau, G., Gicquel, L., and Duchanine, F., "Large Eddy Simulations of the Combustor Turbine Interface: Study of the Potential and Clocking Effects," ASME Turbo Expo 2016, No. GT2016-56443, Seoul, South Korea, June 1317, 2016.

${ }^{10}$ Roux, S., Cazalens, M., and Poinsot, T., "Outlet-Boundary-Condition Influence for Large Eddy Simulation of Combustion Instabilities in Gas Turbines," Journal OF Propulsion and Power, Vol. 24, 2008, pp. 541-546.

${ }^{11} \mathrm{He}$, L., Menshikova, V., and Haller, B. R., "Effect of Hot-Streak Counts on Turbine Blade Heat Load and Forcing," Journal of Propulsion and Power, Vol. 23, 2007, pp. 1235-1241.

${ }^{12}$ Quresh, I., Smith, A. D., Chana, K. S., and Povey, T., "Effect of Temperature Nonuniformity on Heat Transfer in an Unshrouded Transonic HP Turbine: An Experimental and Computational Investigation," Journal of Turbomachinery, Vol. 134, 2012, 011005-011005-12.

${ }^{13}$ Pope, S. B., "A Monte Carlo Method for the PDF Equations of Turbulent Reactive Flow," Combustion Science and Technology, Vol. 25, 1981, pp. 159-174.

${ }^{14}$ Magnussen, B. and Hjertager, B. H., "On the mathematical modeling of turbulent combustion with special emphasis on shoot formation and combustion," Sixth Symposium (International) on combustion, 1976, pp. 719-729.

${ }^{15}$ Kerstein, A., "Linear-eddy model of turbulent scalar transport and mixing," Combustion Science and Technology, Vol. 60, 1988, pp. 391-421.

${ }^{16}$ Menon, S. and Kerstein, A., "Stochastic simulation of the structure and propagation rate of turbulent premixed flames," Twenty-fourth Symposium (International) on combustion, 1992, pp. 443450.

${ }^{17}$ Raju, M., "A Lagrangian Spray solver - User's manual," No. NASA/CR97-206240, 1997.

${ }^{18}$ Raju, M., "LSPRAYII: A Lagrangian Spray Module," No. NASA/CR2004-212958, 2004.

${ }^{19}$ Shih, T.-H., Chen, K.-H., and Liu, N.-S., "A Non-linear k-epsilon Model for Turbulent Shear Flows," $34 t h$ AIAA/ASME/SAE/ASEE Joint Propulsion Conference \&S Exhibit, No. AIAA 1998-35684, Cleveland, OH, July 13-15 1998.

${ }^{20}$ Chen, K.-H. and Liu, N.-S., "Evaluation of A Non-Linear Turbulence Modeling Using Mixed Volume Unstructured grids," 36th AIAA Aerospace Sciences Meeting and Exhibit, No. AIAA 1998-0233, Reno, NV, January 12-15 1998.

${ }^{21}$ Iannetti, A. C. and Moder, J. P., "Comparing Spray Characteristics from Reynolds Averaged Navier-Stokes (RANS) National Combustion Code (NCC) Calculations Against Experimental Data for a Turbulent Reacting Flow," No. NASA/CR2010-216735, 2010.

${ }^{22}$ Wey, T. and Liu, N.-S., "Updates to Simulation of a Single-Element Lean-Direct Injection Combustor Using Arbitrary Polyhedral Meshes," AIAA, Kissimmee, FL, Jan 2015, pp. AIAA 2015-0099.

${ }^{23}$ Kumud, A. and Chen, K.-H., "Unsteady-Flow Computations for the NCC," AIAA, Reno, NV, Jan 2001, pp. AIAA 2001-0972.

${ }^{24}$ Miki, K., Moder, J., and Liu, M.-L., "Enhancement of the Open National Combustor Code (Open NCC) and Initial Simulation of Energy Efficient Engine," 52 ${ }^{\text {nd }}$ AIAA Joint Propulsion Conference, No. AIAA-2016-4651, Salt Lake City, UT, July 2016.

${ }^{25}$ Wey, T. and Liu, N.-S., "Updates to Simulation of a Single-Element Lean-Direct Injection Combustor Using a Polyhedral Mesh Derived from Hanging-Node Elements," AIAA, National Harbor, Maryland, Jan 2014, pp. AIAA 2014-1385. 
${ }^{26}$ Franzelli, B., Riber, E., Sanjos, M., and Poinsot, T., "A two-step chemical scheme for keroseneair premixed flames," Combustion and Flame, Vol. 157, 2010, pp. 1364-1373.

${ }^{27}$ Bradley, D., Gaskella, P., Gua, X, J., Lawesa, M., and Scotta, M. J., "Premixed turbulent flame instability and NO formation in a lean-burn swirl burner," Combustion and Flame, Vol. 115, 1998, pp. 515-538.

${ }^{28}$ Lee, S.-Y., Seo, S., Broda, J., Pal, S., and Santoro, R., "An experimental estimation of mean reaction rate and flame structure during combustion instability in a lean premixed gas turbine combustor," Proceedings of the Combustion Institute, Vol. 28, 2000, pp. 775-782.

${ }^{29}$ Leong, M. Y., Samuelsen, G. S., and Holdeman, J. D., "Optimization of Jet Mixing into a Rich , Reacting Crossflow," Journal of Propulsion and Power, Vol. 16, 2000. 
Appendix

\section{A. Appendix}

The mass flow rates are summarized in Fig.19 and Table. 5.

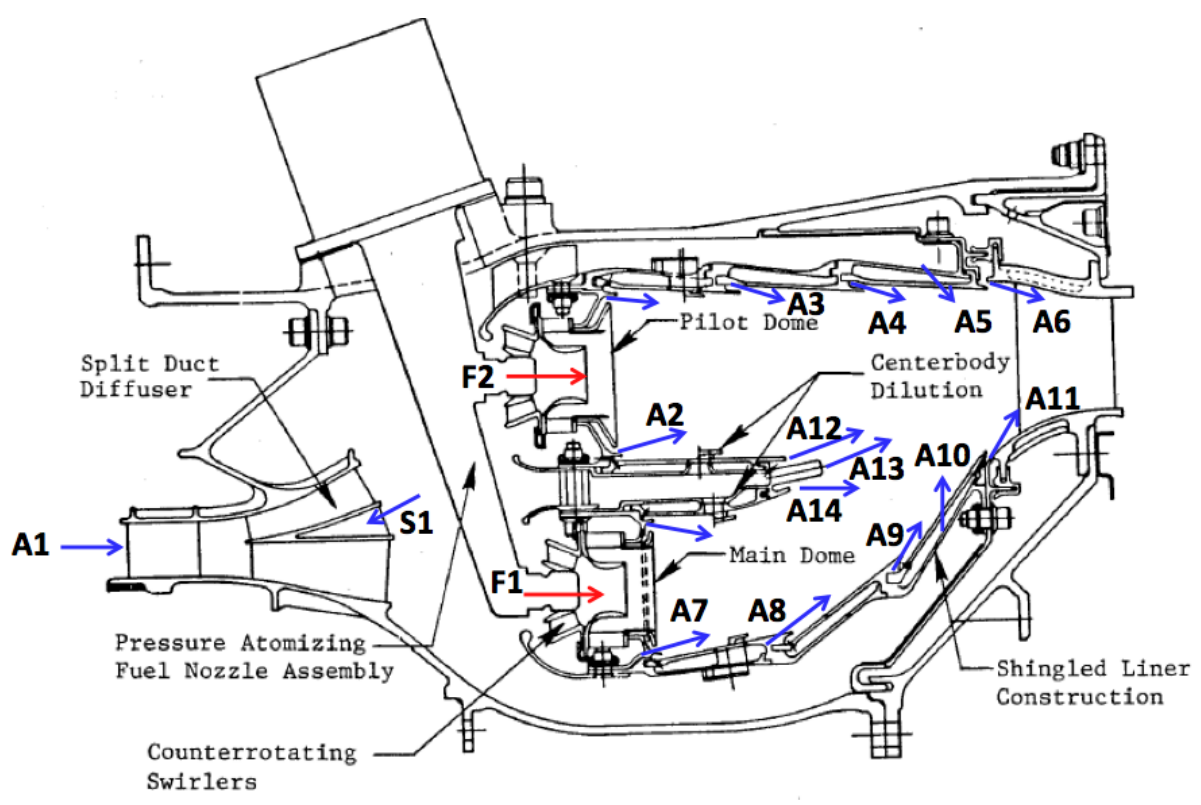

Figure 19. Cross section of the sector $\mathrm{E}^{3}$ combustor and injectors.

Table 5. Flow area distribution. ${ }^{6}$

\begin{tabular}{c|ccc}
\hline Name & Index & Gas & Mass flow rate $[\mathrm{kg} / \mathrm{s}]$ \\
\hline Inflow & A1 & Air & 0.26 \\
\hline Main dome & F1 & Fuel & 0.00182 \\
Pilot dome & F2 & Fuel & 0.00182 \\
\hline Diffuser Bleed & S1 & Air & -0.018 \\
\hline Pilot splash plate cooling & A2 & Air & 0.0104 \\
Outer liner cooling 1 & A3 & Air & 0.0053 \\
Outer liner cooling 2 & A4 & Air & 0.0053 \\
Outer liner trim cooling & A5 & Air & 0.0018 \\
Outer liner cooling 3 & A6 & Air & 0.0024 \\
Main splash plate cooling & A7 & Air & 0.0116 \\
Inner liner cooling 1 & A8 & Air & 0.0096 \\
Inner liner cooling 2 & A9 & Air & 0.0056 \\
Inner liner trim cooling & A10 & Air & 0.0018 \\
Outer liner cooling 3 & A11 & Air & 0.0024 \\
Centerbody outer cooling & A12 & Air & 0.0018 \\
Centerbody mid cooling & A13 & Air & 0.0024 \\
Centerbody Inner cooling & A14 & Air & 0.0024 \\
\hline
\end{tabular}

